Article

\title{
Coastal Vulnerability Assessment Due to Sea Level Rise: The Case Study of the Atlantic Coast of Mainland Portugal
}

\author{
Carolina Rocha ${ }^{1}(\mathbb{D})$, Carlos Antunes ${ }^{1,2, *(D)}$ and Cristina Catita ${ }^{1,2}$ \\ 1 Faculdade de Ciências, Universidade de Lisboa, 1749-016 Lisboa, Portugal; csirocha@fc.ul.pt (C.R.); \\ cmcatita@fc.ul.pt (C.C.) \\ 2 Instituto Dom Luiz, Universidade de Lisboa, 1749-016 Lisboa, Portugal \\ * Correspondence: cmantunes@fc.ul.pt; Tel.: +351-21-7500839
}

Received: 20 December 2019; Accepted: 26 January 2020; Published: 28 January 2020

\begin{abstract}
Sea level rise, a consequence of climate change, is one of the biggest challenges that countries and regions with coastal lowlands will face in the medium term. This study proposes a methodology for assessing the vulnerability to sea-level rise on the Atlantic coast of mainland Portugal. Some scenarios of extreme sea levels for different return periods and extreme flooding events were estimated for 2050 and 2100, as proposed by the European Directive 2007/60/EC. A set of physical parameters are considered for the multi-attribute analysis based on the Analytic Hierarchy Process, in order to define a Physical Vulnerability Index fundamental to assess coastal vulnerability. For each sea-level rise scenario, coastal vulnerability maps, with a spatial resolution of $20 \mathrm{~m}$, are produced at a national scale to identify areas more vulnerable to sea-level rise, which are key elements for triggering adaptation plans for such vulnerable regions. For 2050 and 2100, it is estimated that there will be 903 and $1146 \mathrm{~km}^{2}$ of vulnerable areas, respectively; the Lisbon district being identified as the most vulnerable in both scenarios. Results are available as a Web Map Service for the Portuguese public entities, and through a web map viewer for the public and communities in general.
\end{abstract}

Keywords: European Directive 2007/60/EC; sea-level rise; coastal vulnerability; GIS; Portugal Coast; Web Map Service; WebViewer

\section{Introduction}

Sea-level rise (SLR) resulting from climate change is a phenomenon that cannot be prevented. According to the Intergovernmental Panel for Climate Change (IPCC) [1], it "will continue to rise well beyond 2100 (high confidence). Increasing global warming amplifies the exposure of small islands, low-lying coastal areas and deltas to the risks associated with sea level rise for many human and ecological systems, including increased saltwater intrusion, flooding and damage to infrastructure". Areas within $100 \mathrm{~km}$ of the coastline comprise most of the countries' economic activities, as well as around $40 \%$ of the world's population [2]. In the European Union (EU), approximately half of the population lives within just $50 \mathrm{~km}$ of the coastline [3] and 19\% (around 86 million people) live within $10 \mathrm{~km}$ of coastline [4]. It is likely that such numbers might be higher in the future due to increasing migration, industrialization, and urbanization in coastal areas, resulting in an increase in human susceptibility to coastal flooding and erosion, especially in low-lying floodplains [5-7]. The SLR susceptibility will soon result in people displacement, severely compromising national economic activities. The high demographic exposure of coastal populations and communities sets a high-risk level due to the potential damage of coastal infrastructures and facilities, as well as potential real estate economic depreciation. Therefore, the vulnerability assessment of coastal zones due to SLR flooding plays a very important role for coastal flooding risk assessment and adaptation measures planning. 
In 2007, the EU published the Flood Directive (Directive 2007/60/CE), which essentially establishes the framework for the assessment and management of all inland and coastal watercourses that are at risk of flooding for the purpose of mitigating and reducing the risks to human health, environment, cultural heritage, and economic activity. Determining the entire extent of floodable area due to climate change, its assets, and humans at risk is therefore a priority. To comply with this Directive, the EU member states have, in a first phase (until 2011), to identify the river basins and associated coastal areas at risk of flooding. For these areas, the EU Directive recommends the development of flood risk mapping by 2013, as well as the preparation of management plans focused on prevention, protection, and preparedness, by 2015 [8]. In Portugal, this Directive was transposed into the national law in 2010 through Decree-Law no. 115/2010, 22 October.

In mainland Portugal, flood risk mapping is under the competency of the Portuguese Environment Agency (APA) as the national water authority. The DL 115/2010 creates a National Commission for Flood Risk Management (CNGRI) in which APA, the National Authority for Civil Protection, the Directorate-General for the Territory, and the municipalities are represented. In terms of implementation, in February 2014, APA launched a public tendering procedure for the elaboration of risk flood maps. From that point up till now, there have been two regional special coastline programs implemented with the respective coastal risk assessment maps, one approved and the other remaining under work. All products in the scope of this legislation are available at the SNIAmb geoportal [9].

Scientific documentation refers to the term "vulnerability" in different ways, leading to different interpretations. According to the Intergovernmental Panel for Climate Change (IPCC), "vulnerability encompasses a variety of concepts and elements including sensitivity or susceptibility to harm and lack of capacity to cope and adapt". On the other hand, IPCC defines coastal vulnerability as the "propensity or predisposition to be adversely affected" by a natural hazard [10].

Over the past two decades, scientists have developed different approaches to identify coastal vulnerability. The most common coastal vulnerability assessment is based on the calculation of an index that aggregates a set of parameters (variables) that represent several spatial entities (geographic data) that contribute to coastal vulnerability. Gornitz et al. [11] proposed the first Coastal Vulnerability Index (CVI), composed of seven variables as indicators of physical vulnerability due to the SLR impacts in the United States of America (USA). These variables consisted of relief (elevation), lithology, geomorphology, erosion/accretion, tidal range, wave height, and relative sea-level changes. This methodology has been improved by Gornitz et al. [12], who considered thirteen variables grouped into three categories: erosion (geology, landform, shoreline erosion and wave height), permanent inundation (elevation and local subsidence) and episodic inundation (tropical storm probability, hurricane probability, hurricane frequency-intensity, tropical cyclone forward velocity, extratropical cyclones, hurricane storm surge, and tide range). In both methods, each variable was rated on a scale of 1 to 5 to express its contribution to coastal vulnerability, 5 being the highest and 1 the lowest level. The Gornitz et al. [12] method segments the coastline assigning a vulnerability index value to each coastal segment, being the CVI defined by the square root of the geometric mean, or through the square root of the product of the ranking factors, divided by the number of variables considered. Following these publications [11,12], other studies have been developed for North America and some European and Asian countries, using specific methodologies to evaluate coastal vulnerability indices applied at regional or local scales (e.g., [13-26]).

In Portugal, coastal vulnerability has been studied also at regional and local scales. Coelho [27] proposed a methodology, revised by Coelho et al. [28], to calculate the CVI based on nine vulnerability parameters including geology, geomorphology, land use, anthropogenic actions, elevation, distance to coastline, maximum tidal range, maximum significant wave, and erosion rate. Pereira and Coelho [29] calculated the vulnerability within a 2-km range from the shoreline segment between Espinho and Mira (north of mainland Portugal) based on the method proposed by Coelho [27].

The coastal vulnerability of Ria Formosa (south of mainland Portugal) was evaluated by Ceia et al. [30] who identified the areas more vulnerable to risk by assessing the evolution of the 
barrier island system (for the time period between 1940 and 2008). They also determined which interventions would be necessary to protect those areas. Their methodology considered as spatial parameters for the shoreline evolution, the overwash vulnerability, the human occupation, the footpaths, the vegetation, and the interventions, and rated each coastline segment (fourteen in total) based on a scale from 1 (null) to 5 (extremely high) regarding coastal vulnerability.

Martins et al. [31] have studied the vulnerability of the coastal stretch between Porto de Mós and the Falésia beaches in Algarve (south of mainland Portugal), corresponding to an area of $52 \mathrm{~km}$ in length and $500 \mathrm{~m}$ in width, measured from the coastline to the inland area. This study follows an approach based on Cellular Automata. A geographical database was created with two types of variables: (1) natural/physical vulnerability (lithology, coastal systems, and hydrology) and (2) human factors (highway/railway network, population density, population growth, and urban land cover). Segments were rated on a score/vulnerability degree from 1 (very low) to 5 (very high).

The vulnerability and the hazard of flooding by SLR in the central Algarve (southern mainland Portugal), between the cities of Portimão and Tavira, was studied by Martínez-Graña et al. [32]. The vulnerability index was calculated using lithology, geomorphology, slopes, elevations, distances, bathymetry, variations of the coastline, wave height and activity, variations of sea level, and tidal range for several time horizons.

The common denominator of the previously mentioned studies is the spatial unit for the respective CVI calculation, which limits the vulnerability assessment to a constant strip along the coastline. That is, the coastline is segmented into sectors of equal lengths (e.g., $500 \mathrm{~m}$ ) and, for each sector, the CVI is determined considering the specific selected parameters. The major limitation of this method is its inability to represent the CVI spatial variability within each sector which results from the lack of detailed spatial data. Another limiting aspect is the absence of a prior classification of the study areas into flooded or non-flooded zones, being the methodology applied equally for both cases, with the consequent risk of considering non-flooded zones as very vulnerable.

Considering such limitations, the present study defines a methodology to assess Coastal Vulnerability at a national scale, based on projected SLR and extreme flood scenarios forced by extreme events with specific return periods, following the EU Directive guidelines. Coastal vulnerability is calculated on a high spatial resolution basis $(20 \mathrm{~m})$, for areas along the Atlantic Coast of Mainland Portugal (ACMP) that are susceptible to extreme flooding scenarios due to future SLR [33]. In order to make it suitable for a national scale analysis, a Physical Vulnerability Index (PVI) is generated to classify areas vulnerable to coastal flooding, considering five levels of importance. The PVI is obtained through the weighted average of the Extreme Flood Hazard Index (EFHI) and six physical parameters (hydrographic network, distance to the coastline, coastal type, solid geology, drift geology, and land use) weighted through a multicriteria analysis process. The followed weight parameters approach was based on the analytic hierarchy process (AHP) of Saaty [34]. Some authors argue that the CVI must consider both physical and socioeconomic factors. Thus, in this study, mostly physical factors are considered for the index, and for that reason, the authors called it the PVI instead of CVI.

This is an innovative study for Portugal not only because of the methodological approach for determining SLR coastal vulnerability but also because it is the first study that meets the EU Directive guidelines, with a high spatial resolution, which rigorously analyzes and classifies the SLR vulnerability in the ACMP at a national scale.

The manuscript is organized as follows: Section 2 presents the study area and the dataset, Section 3 describes the methodology, Section 4 presents the results, and in Section 5, some conclusions are drawn.

\section{Study Area and Datasets}

\subsection{Study Area}

The Portuguese west coast extends approximately in the NS direction, from the mouth of the Minho River $\left(41^{\circ} 52^{\prime} \mathrm{N}, 8^{\circ} 52^{\prime} \mathrm{W}\right)$ to the St. Vincent Cape $\left(37^{\circ} 01^{\prime} \mathrm{N}, 9^{\circ} 00^{\prime} \mathrm{W}\right)$, while the southern coast 
extends from St. Vincent Cape to the mouth of the Guadiana River ( $37^{\circ} 14^{\prime}$ N, $7^{\circ} 22^{\prime}$ W) [35] (Figure 1). The ACMP extends from south of the mouth of the Minho River to the western mouth of the Guadiana River for about $987 \mathrm{~km}$.

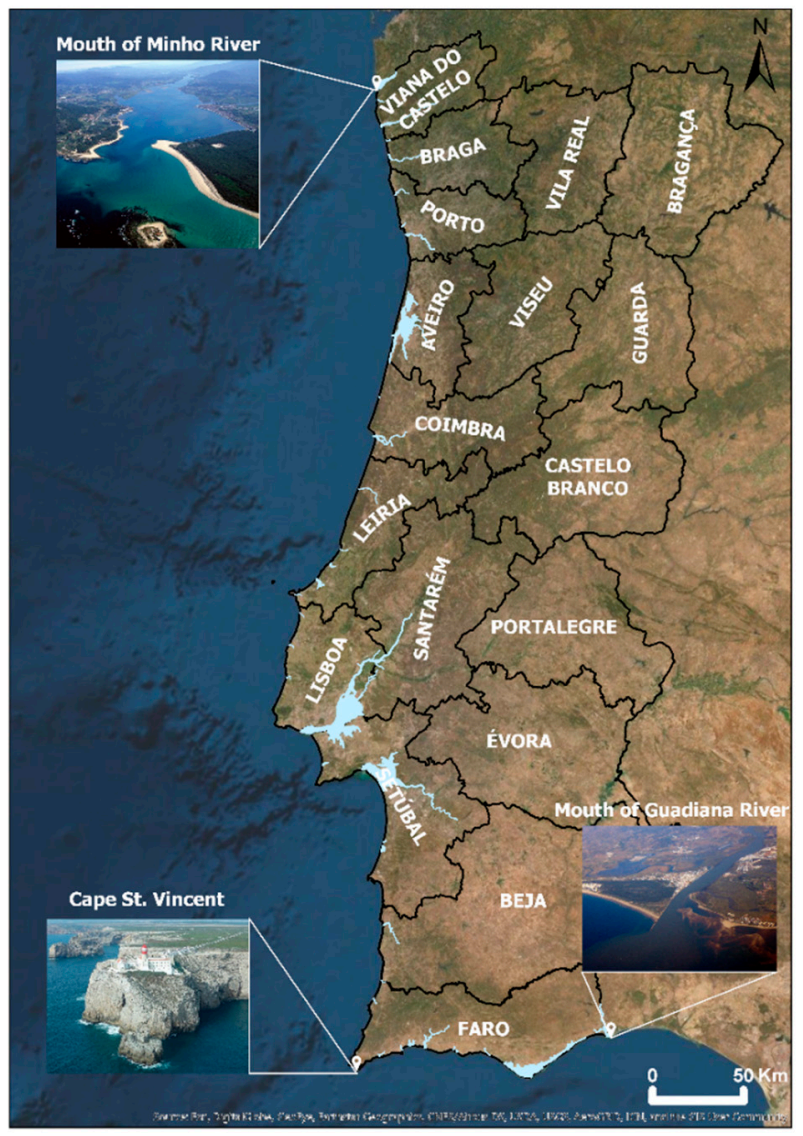

Figure 1. The Atlantic Coast of Mainland Portugal with district limits (black lines) and main coastal rivers (light blue polygons).

The Portuguese coastline contains extensive sandy beaches backed by dunes, high cliffs, bays, estuaries, lagoons, and barrier islands, and it hosts about $75 \%$ of the population, major political decision-making centers, commercial and industrial hubs, and employment opportunities [36].

The main economic activities in these areas are maritime transport, port activities, tourism, bathing and leisure activities, boating, fishing, aquaculture, saliculture, mineral and energy activities. These activities contribute to about $85 \%$ of the national Gross Domestic Product (GDP) and, as such, are highly strategic activities for the country [37].

\subsection{Datasets}

According to the required accuracy and positional detail, the SLR vulnerability assessment can be applied at national, regional (district or municipality) or local scale (a coastal sector in a specific municipality or parish) [38]. Depending on the level of detail, hazards associated with SLR and extreme coastal flooding should be properly considered as well as spatio-temporal data availability and its resolution.

Available data strongly condition the methods to be applied for vulnerability assessment. Thus, in this study, six physical parameters were selected to assess the PVI. Table 1 shows the data used in this study, the respective data sources, and some of its characteristics. All spatial data are in the PT-TM06/ETRS89 coordinate reference system (EPSG: 3763). 
Table 1. Data used in the study, as well as its source and some characteristics.

\begin{tabular}{|c|c|c|}
\hline Parameter & Data Source & Characteristics \\
\hline Hydrographic Network & CIGeoE, 2016 & $\begin{array}{l}\text { Scale: 1:25,000-Tagus Estuary, } \\
\text { Aveiro, and Formosa Lagoons; } \\
\text { Others: manually vectorized. }\end{array}$ \\
\hline Coastline & IH, 2011 & Scale: $1: 25,000$ \\
\hline Lithological chart & APA, 2015 & Scale: $1: 1,000,000$ \\
\hline $\begin{array}{l}\text { Land Use } \\
\text { (COS2007) }\end{array}$ & DGT, 2014 & Level 1 and 2 \\
\hline $\begin{array}{l}\text { Administrative Units } \\
\text { (CAOP2015) }\end{array}$ & DGT, 2015 & $\begin{array}{l}\text { Delimitation of the administrative } \\
\text { districts. }\end{array}$ \\
\hline Statistical Subsection & INE, 2011 & $\begin{array}{l}\text { Census data from Census } 2011 \\
\text { (population and buildings) }\end{array}$ \\
\hline
\end{tabular}

Data were mostly obtained from public domain sources and official and unofficial information provided by different national institutions (e.g., the Portuguese Environment Agency-APA, the Directorate General for Territory_DGT, the Hydrographic Institute-IH, the Military Geospatial Information Center-CIGeoE and the National Statistical Institute-INE). A geospatial database, built in a Geographic Information System (GIS), was produced to store all spatial data (e.g., hydrographic network, administrative units), as well as alphanumeric information (e.g., census data), facilitating the spatial data harmonization.

\section{Physical Vulnerability Index Assessment}

The methodology followed for the PVI calculation combines an Extreme Flood Hazard Index (EFHI) [33], calculated for the ACMP, and a set of physical parameters considered relevant for the assessment of vulnerability to extreme flooding and SLR at the national scale. Figure 2 shows the methodology workflow with the corresponding steps, which are described in the following subsections.

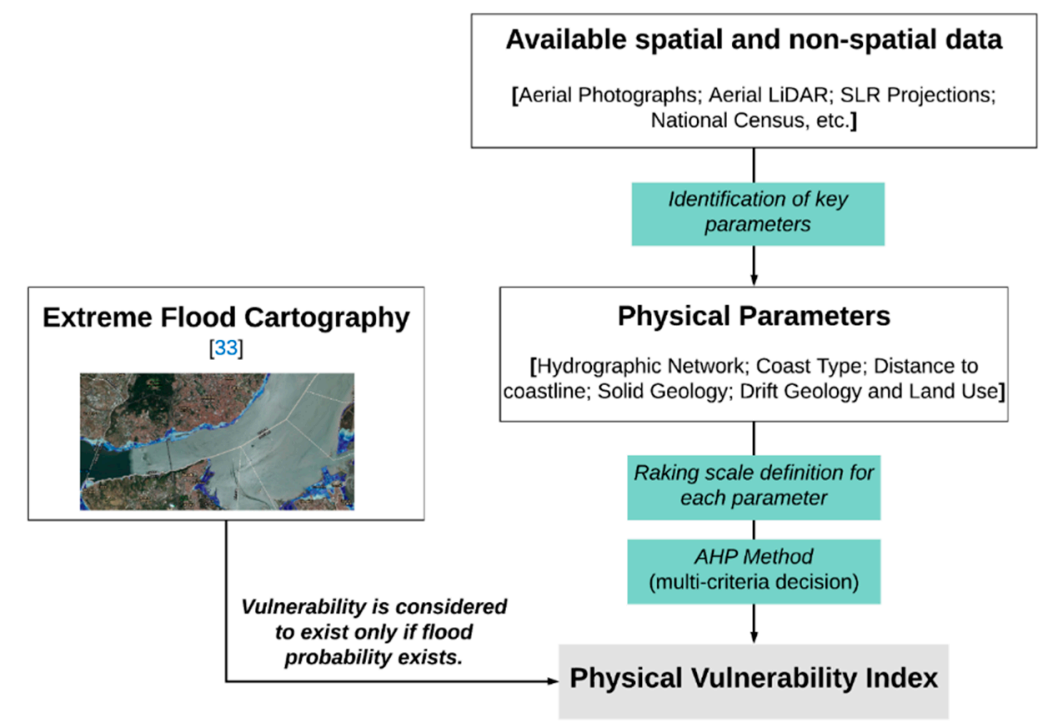

Figure 2. Flow diagram summarizing the methodology adopted in this study for the Physical Vulnerability Index calculation based on the extreme flood cartography of Antunes et al. [33].

Physical vulnerability focuses on determining geographical susceptibility to SLR and extreme flooding in the actual coastal environment, which includes the internal and external physical characteristics of the system, defined through coastal characteristics and coastal forcing [38]. The coastal forcing parameter used in this study is the one given by the EFHI in Antunes et al. [33], which results from the SLR projections in Antunes [39]. 
Since EFHI refers to the actual coastal topography given by a recent digital terrain model (DTM from 2008) without any future morphodynamics [33], the PVI only assesses the actual coastal vulnerability due to the future threat of SLR and extreme flooding. Being quite impossible to estimate or predict a future DTM, based on a nation-wide morphodynamical evolution for 2050 and 2100, the geospatial assessment of vulnerability to SLR can only be evaluated based on an actual topographic model. This means that future coastal erosion cannot be directly considered on current vulnerability assessments, but only indirectly through weighted physical parameters of solid geology and drift geology in the PVI formulation, as is done by McLaughlin and Cooper [38].

\subsection{Extreme Flood Hazard Index (EFHI)}

The EFHI is an index that represents the probability of flooding in a coastal area [33]. This index was developed and calculated by Antunes et al. [33], who applied it first along the ACMP coastal zone. It uses a probabilistic rather than a deterministic approach and classifies the flood hazard into five classes of probability, each one corresponding to a $20 \%$ interval. The SLR scenarios and the respective uncertainty used and applied by Antunes et al. [33] to calculate the EFHI were based on the study of Antunes [39]. The EFHI is classified for an extreme tidal maximum level by five hazard classes ranging from 1 (Very Low) to 5 (Extreme). The probabilistic approach in the EFHI determination by Antunes et al. [33] is fundamental to enable its application in the PVI normalized formulation and is consistent with future coastal risk assessment.

Antunes et al. [33] classified different SLR projections based on Antunes [39], IPCC, and National Oceanic and Atmospheric Administration (NOAA) projections. The probability range applied by the authors, where the uncertainty is used to evaluate the confidence interval up to $99.9 \%$, includes not only the IPCC estimates but also the most recent projections. Moreover, in such an approach of Antunes et al. [33], not only the SLR uncertainty is included but also the uncertainty of the tidal model and storm surge estimates.

Extreme flooding modeled in [33] and normalized through the EFHI includes SLR, local astronomical tides for each region, and storm surges. An additional extreme flooding scenario, with wave setup for open coast and local wind setup for estuaries and lagoon systems, was also considered by the authors; however, the current vulnerability assessment only considers the EFHI for the scenario without wave and wind setup. Storm surges were statistically modeled by Antunes et al. [33] with historical tide gauge data from the four tide gauges considered. The total runup (including incident runup) was not considered for different reasons, namely, the geographical scale, as well as the fact that the EFHI corresponds to a hydrostatic rather than a hydrodynamical model. For more details about the EFHI methodology, the study [33] should be consulted.

This index is the basis for the production of probabilistic flood maps, to which an updated topographic model was used (obtained from an 2008 aero-photogrametric model with an original spatial resolution of $2 \mathrm{~m}$; see [33] for more detailed information), without inferring any coastal profile morphodynamics nor considering coastline retreat due to present and future erosion and SLR. The generated maps allowed the quantification and the classification of the flooding area for each SLR scenario, thus being the basis for the coastal vulnerability assessment.

The main results in Antunes et al. [33] show that, for the year 2050, a total of $903 \mathrm{~km}^{2}$ of the ACMP is potentially affected by extreme flooding due to SLR, with the districts of Lisbon, Faro, and Aveiro being the most affected with 221, 182, and $172 \mathrm{~km}^{2}$ of flooded area, respectively. For 2100 (e.g., Figure 3), those values rise to $1146 \mathrm{~km}^{2}$ of the total area and 250, 211, and $219 \mathrm{~km}^{2}$, respectively, for the same districts (Lisbon, Faro, and Aveiro). 


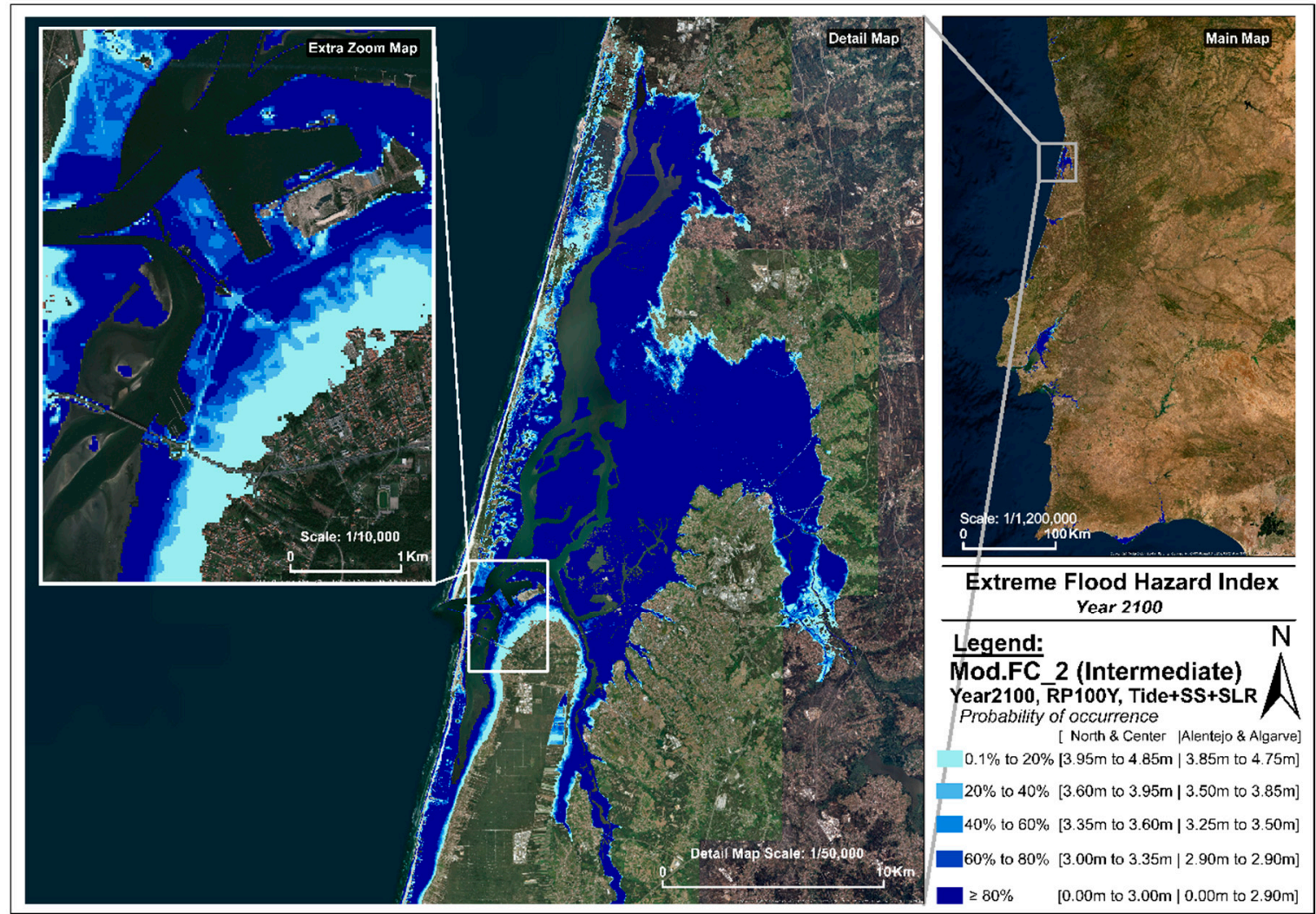

Figure 3. Portuguese coastal flooding extreme scenarios for 2100 SLR and 100-yr return period, within a zoomed image of the Aveiro inland lagoon (Ria de Aveiro). Source: Antunes et al. [33].

These results were provided as a Web Map Service (WMS) to the Ministry of Environment under a protocol signed between the General Secretariat of the Ministry of Environment, the Portuguese Association of Insurers, and the Research Group "Climate Change Impacts, Adaptation and Modelling-CCIAM" of the Lisbon University.

\subsection{Physical Parameters}

Different sets of physical parameters used to determine physical vulnerability can be found in the literature, each one with a specific contribution for the susceptibility to either extreme or frequent flooding. However, access and availability to geographical data, as well as the quality and spatial resolution, condition in most cases their usability in an application. Additionally, the importance or the weight of each parameter must be considered so the results can rely on a more realistic assessment.

Table 2 shows how each parameter is classified, maintaining the rationale that each parameter must be rated on a scale from 1 to 5 to express its PVI contribution, with 1 corresponding to Very Low and 5 corresponding to Extreme vulnerability.

Since EFHI represents the coastal forcing in PVI, the six additional physical parameters, based on the classification of McLaughlin and Cooper [38], represent coastal (hydrographic network, coast type, distance to coastline, solid geology, and drift geology) and social-economic (land use) characteristics.

The following sub-sections describe the procedure used in GIS to classify each of these parameters. 
Table 2. Classification of physical vulnerability parameters for mainland Portugal, ranging from 1 (Very Low) to 5 (Extreme).

\begin{tabular}{|c|c|c|c|c|c|c|}
\hline \multicolumn{2}{|c|}{ Physical Parameter } & \multirow{2}{*}{$\frac{\text { 1-Very Low }}{200-300 \mathrm{~m}}$} & \multirow{2}{*}{$\frac{\text { 2-Low }}{150-200 \mathrm{~m}}$} & \multirow{2}{*}{$\frac{\text { 3-Medium }}{100-150 \mathrm{~m}}$} & \multirow{2}{*}{$\begin{array}{l}\text { 4-High } \\
50-100 \mathrm{~m}\end{array}$} & \multirow{2}{*}{$\frac{\text { 5-Extreme }}{\leq 50 \mathrm{~m}}$} \\
\hline Hydrographic & Dist. & & & & & \\
\hline Network & Slope & $\geq 3^{\circ}$ & $2.0-3.0^{\circ}$ & $1.5-2.0^{\circ}$ & $0.5-1.0^{\circ}$ & $\leq 0.5^{\circ}$ \\
\hline \multicolumn{2}{|c|}{ Coast Type } & Rock Cliff Coast & & & & Low and sandy coast \\
\hline \multicolumn{2}{|c|}{ Distance to Coastline } & $\geq 1000 \mathrm{~m}$ & 200-1000 m & $50-200 \mathrm{~m}$ & $20-50 \mathrm{~m}$ & $\leq 20 \mathrm{~m}$ \\
\hline \multicolumn{2}{|c|}{ Solid Geology } & $\begin{array}{c}\text { Plutonic, } \\
\text { metamorphic and } \\
\text { volcanic rocks }\end{array}$ & & $\begin{array}{c}\text { Sandstone and } \\
\text { consolidated } \\
\text { sedimentary } \\
\text { formations }\end{array}$ & & $\begin{array}{c}\text { Fine and coarse } \\
\text { unconsolidated } \\
\text { sedimentary } \\
\text { formations }\end{array}$ \\
\hline \multicolumn{2}{|c|}{ Drift Geology } & Urban or rock & Stone or clay & & $\begin{array}{l}\text { Beaches or } \\
\text { sediments }\end{array}$ & $\begin{array}{c}\text { alluvium; loose sand } \\
\text { or gravels }\end{array}$ \\
\hline Land Use (le & 1 and 2) & $\begin{array}{c}\text { Water bodies; } \\
\text { sparse vegetation; } \\
\text { swamp or bare } \\
\text { rock }\end{array}$ & $\begin{array}{l}\text { Coastal } \\
\text { sands }\end{array}$ & Forest & Agriculture & $\begin{array}{l}\text { Urban and industrial } \\
\text { infrastructures }\end{array}$ \\
\hline
\end{tabular}

\subsubsection{Hydrographic Network}

The terrain slope, evaluated from the DTM, combined with the distance to the river network enables the identification of near areas, through a compound index of height differences, that are potentially affected by floods, e.g., a river in a valley with a considerable slope has a low vulnerability, unlike a river in a plain where the slope is fairly low. In the latter, if there is a probability of extreme flooding, there is also a high probability of flooding along the shallow flatlands. Finally, the terrain slope allows one to assess not only the relative risk of flooding but also the susceptibility to these flooding events. Thus, regions with the lowest slope should have the most proactive protection and adaptation measures than the steepest regions [17].

Obtaining a hydrographic network with the required accuracy for this type of study is an extremely difficult task since the free available data has low positional accuracy due to its cartographic scale. In order to overcome these limitations, some efforts have been made to manually vectorize (at a minimum scale of 1:800) all the main rivers and water bodies near the ACMP (a total of 34 rivers) except for the Aveiro Lagoon, the Formosa Lagoon and the Tagus River, where the respective 1:25,000 scale cartography was provided by the CIGeoE. Figure 4 shows two examples of free data available at the Environment Atlas site [9] and some positional problems inherent to the inaccuracy of the data.
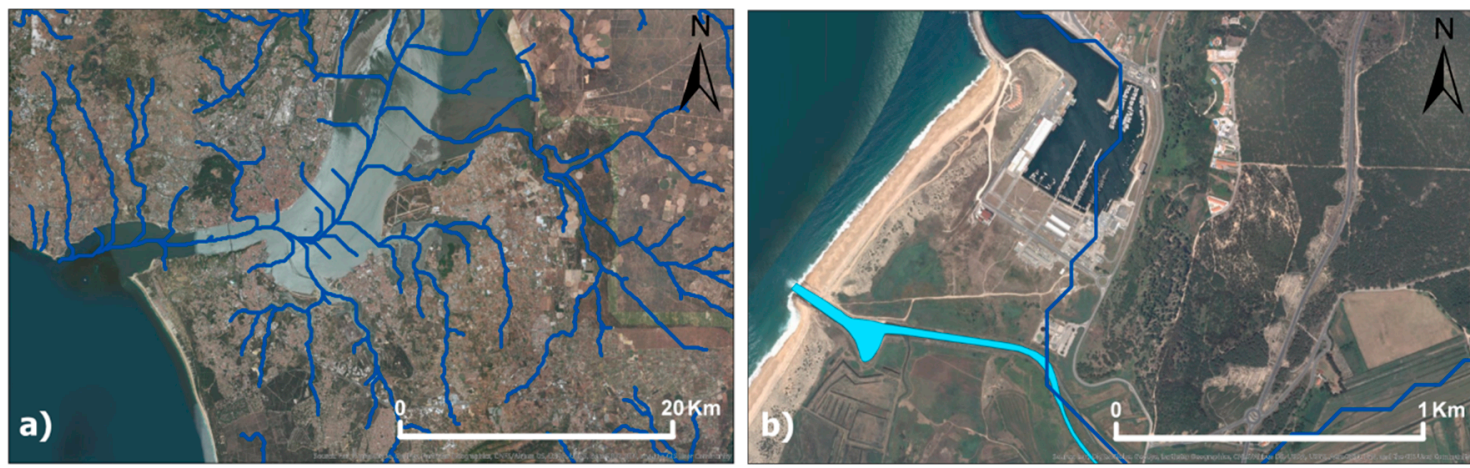

Figure 4. Examples of problems found in the online data available at the Environment Atlas [9]: (a) The hydrographic network of the Tagus river valley available in the Environment Atlas represented by supposed axes of water bodies. (b) The Alcoa river, near the Nazare city, represented in the Environmental Atlas, is shown as a dark blue line, while its manual vectorization is shown as a light blue polygon.

The type of coast varies according to the nature of its rock materials, and although the Portuguese coast has fairly extensive areas dominated by beaches, there are also predominant rocky coastal areas. 
Thus, two types of coast can be defined (Figure 5) the cliff coast and the low sandy coast, which are the two types considered for the PVI calculation.
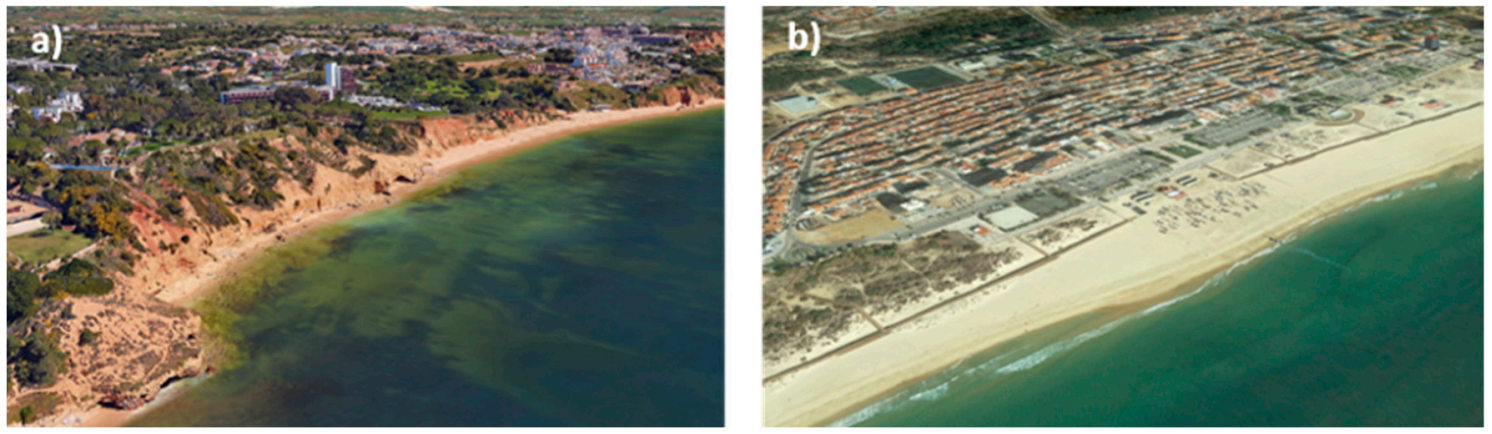

Figure 5. Two types of coast in mainland Portugal: (a) Cliff coast in the Albufeira's Falésia beach, Algarve; (b) low sandy coast in the Manta Rota beach (Vila Real de Santo António), Algarve. Source: Google Earth Pro.

The parameterization of the coast type was defined at the parish level, for which each predominant type was defined. Based on the Portuguese Official Administrative Chart (CAOP2015), it was possible to select only the parishes that contain coastal areas classified according to their type of coast. The rock cliff coast is characterized as being high and having steep reliefs and constituted by rock formations more resistant to erosion and to SLR, therefore its vulnerability classification level is 1 (very low). The low and sandy coast allows the sea to advance faster than in the previous case, and consequently its vulnerability class will be maximum level 5 (Extreme).

\subsubsection{Distance to Coastline}

The distance to the coastline is an important factor in this analysis, as vulnerability increases with the proximity to the shoreline. Under normal conditions, a coastline location is more subject to the energetic forces of the sea, so as the distance to the coastline increases, the erosion and coastal vulnerability decreases.

Figure 6 shows an example of the coastline in the Algarve region (southern Portugal) and the respective distance classes classified according to the values in Table 2.
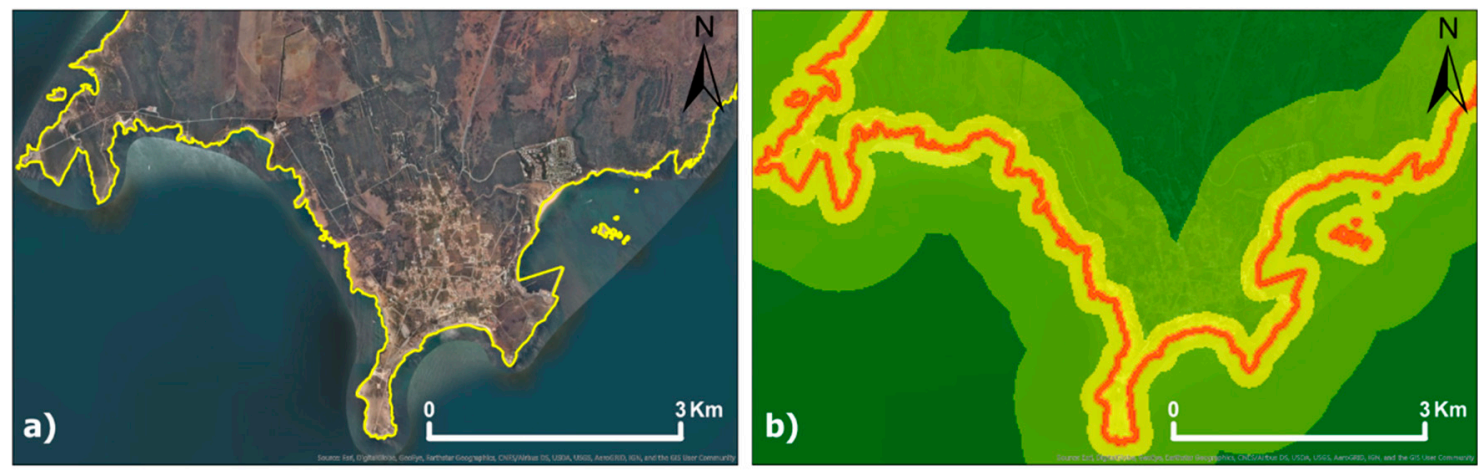

Figure 6. (a) Coastline in the Sagres (southern west Algarve) according to the Hydrographic Institute (IH); (b) Distance to coastline classified according to the values in Table 2: very low-dark green, low-green, medium—yellow, high—orange, and extreme—red.

For the coastline distance calculation, a baseline (vector geometry in a shapefile format) provided by $\mathrm{IH}$, which includes the coastline of Portugal, Spain, and part of Africa, was used. Only the ACPM coastline was extracted from that file, which according to IH, was obtained mainly from the information of the CAOP, and it has been further enhanced with information collected by IH in ports, rivers, 
and lagoons areas. Metadata also provides the associated coastline uncertainty, which presents the minimum accuracy on the 1:25,000 scale.

\subsubsection{Solid Geology and Drift Geology}

The solid geology and drift geology cartography allow the evaluation of the rocks and sediments that form the coastal regions, as well as its classification based on the behavior of those materials when subjected to coastal forcing. For example, magmatic or eruptive rocks are of high hardness and therefore of low vulnerability to erosion, unlike small non-consolidated sediments [27]. Erosional susceptibility (not erosion rates) is classified in the physical vulnerability index context by normalized levels (1,3, and 5), according to the rock hardness. Therefore, unconsolidated sediments (class 5), such as beaches and dunes, are more susceptible to erosion than hard rocks (class 1) or even sandstones and consolidated sediments (class 3). The lithological chart of Portugal provides elements about the country's superficial lithology in which the mother rock, as a formation factor, assumes high importance in the characterization and use of soil [9].

The information for these two parameters is available at the Environment Atlas website in a single shapefile containing thirty-four different lithological complexes. This chart is based on the geological map of Portugal, published in 1972 at a scale of 1:500,000, including sedimentary, metamorphic, and eruptive lithological formations [40]. There are twenty-six complexes belonging to sedimentary and metamorphic rocks and eight belonging to eruptive rocks. The shapefile contains attributes concerning the mother rock formation type and the lithological complexes. Both attributes were used to select areas of solid geology and drift geology to rank them on a scale from 1 to 5 (an example in Figure 7), according to the classification in the Table 2.
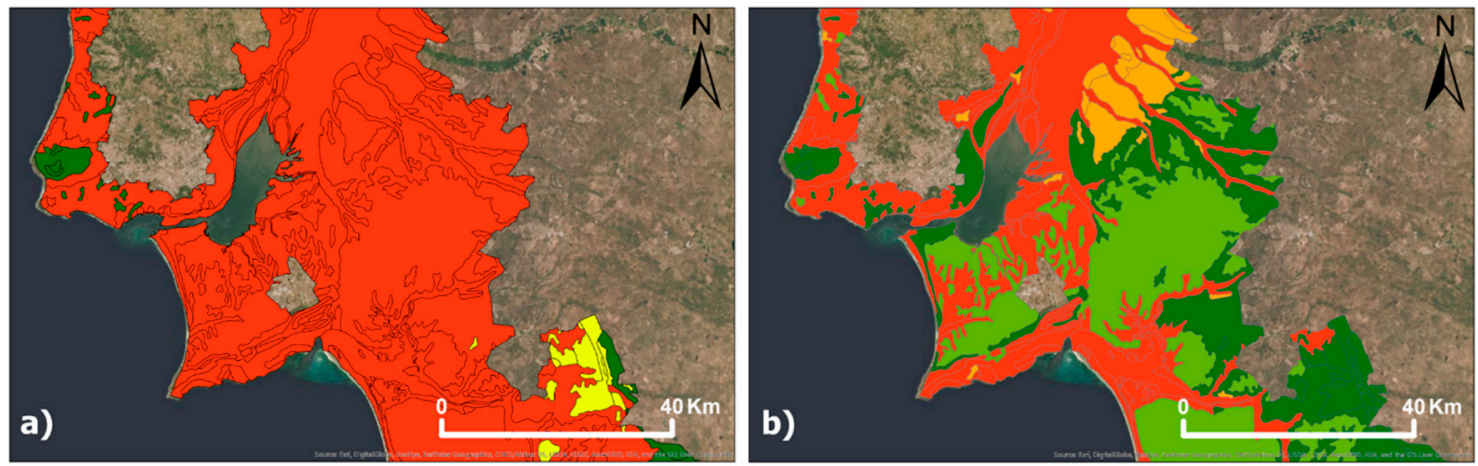

Figure 7. Classification of the Lisbon Region, according to Table 2: very low-dark green, low-green, medium-yellow, high—orange, and extreme-red. (a) Solid geology; (b) drift geology.

\subsubsection{Land Use}

The morphological characteristics of the coast may also be a result of the type of land use. A wooded or a fully paved coast has a distinct behavior regarding to coastal vulnerability. Thus, it is considered that the higher the rate of natural soil changes, the greater is the vulnerability.

Land use information was extracted from the Land Cover Mapping program (COS2007) in Portugal, which is based on the visual interpretation of orthorectified aerial images [41]. The COS nomenclature follows a hierarchy that represents land use/occupation at different levels and classes of thematic detail, where level 1 has 5 classes and level 2 has 193 classes.

In the present study, from the five existing levels, only the first and second were used, corresponding to the less detailed levels, but which perfectly fits the study scale.

Figure 8 shows two examples of the classification in Lisbon (urban area) and Formosa Lagoon (a Natural Park). 

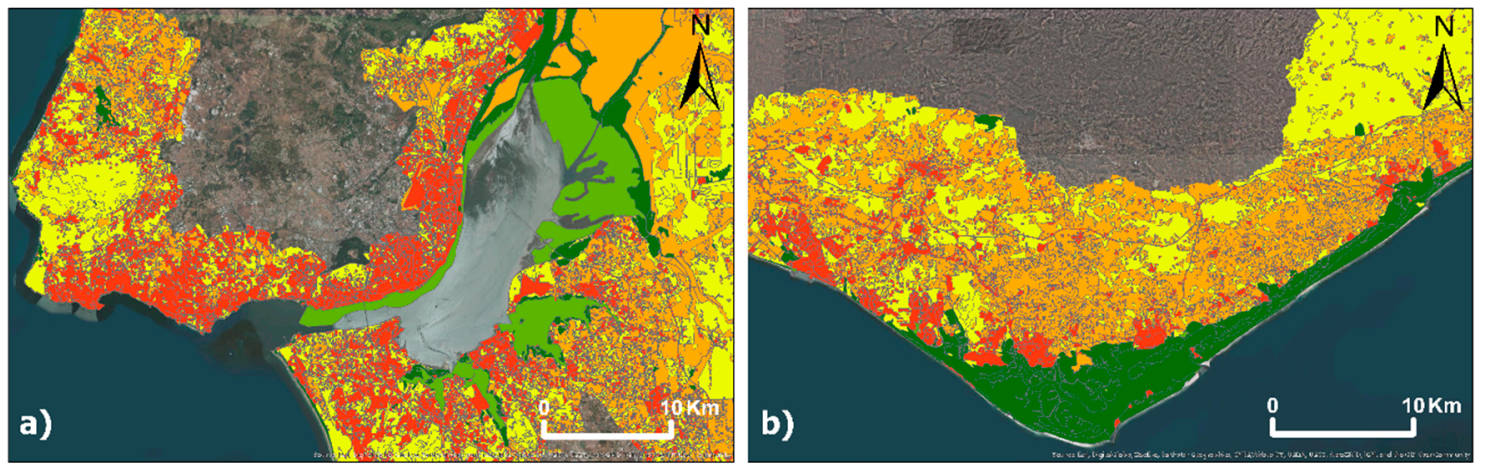

Figure 8. Classification of land use according to Table 2: very low-dark green, low-green, medium—yellow, high—orange, and extreme—red. (a) Lisbon region; (b) Formosa Lagoon—Algarve.

\subsection{Analytical Hierarchical Process}

The analytic hierarchy process (AHP) method was developed by Saaty between 1971 and 1975 . This method is increasingly used in the design of decision support systems based on a multi-attribute approach since it is easy to implement in computer systems and its mathematical model presents a relatively simple algebraic calculation [34]. This method has been used to design decision systems, such as risk zones and landslide susceptibility mapping (e.g., [42-45]), earthquake hazard (e.g., [46]), flood zones (e.g., [47,48]), and coastal vulnerability assessment (e.g., [22,49-53]). The advantages of this method are pointed out in [34].

According to Saaty [34], the logical consistency of the comparison's matrix is guaranteed by the analysis of the "consistency ratio", comparing it with "random consistency". The AHP evaluates the needed weighting factors by means of a preference matrix, where all the selected parameters, considered relevant for a specific study, are compared to each other.

In the present study, pairwise comparisons were carried out for all the parameters involved in the PVI definition and the matrix was completed using scores based on their relative importance according to Saaty's rating scale as shown in Table 3.

Table 3. The fundamental analytic hierarchy process (AHP) scale [34].

\begin{tabular}{|c|c|c|}
\hline $\begin{array}{c}\text { Intensity of Importance on an } \\
\text { Absolute Scale }\end{array}$ & Definition & Explanation \\
\hline 1 & Equal importance & $\begin{array}{l}\text { Two activities contribute equally } \\
\text { to the objective }\end{array}$ \\
\hline 3 & $\begin{array}{c}\text { Moderate importance of one over } \\
\text { another }\end{array}$ & $\begin{array}{l}\text { Experience and judgment strongly } \\
\text { favor one activity over another }\end{array}$ \\
\hline 5 & Essential or strong importance & $\begin{array}{l}\text { Experience and judgment strongly } \\
\text { favor one activity over another }\end{array}$ \\
\hline 7 & Very strong importance & $\begin{array}{l}\text { An activity is strongly favored, } \\
\text { and its dominance demonstrated } \\
\text { in practice }\end{array}$ \\
\hline 9 & Extreme importance & $\begin{array}{l}\text { The evidence favoring one activity } \\
\text { over another is of the highest } \\
\text { possible order of affirmation }\end{array}$ \\
\hline $2,4,6,8$ & $\begin{array}{l}\text { Intermate values between the two } \\
\text { adjacent judgments }\end{array}$ & When compromise is needed \\
\hline Reciprocals & $\begin{array}{l}\text { If activity } i \text { has one of the above } \\
\text { numbers assigned to it when } \\
\text { compared with activity } j \text {, then } j \\
\text { has the reciprocal value when } \\
\text { compared with } i\end{array}$ & - \\
\hline
\end{tabular}


Each physical parameter has been rated pairwise against every other one by assigning a relative importance intensity between 1 and 9 (Table 4), according to the fundamental AHP scale. The intensity of importance attributed to each parameters pair was defined by the authors based on their perception over the relative importance of each parameter for the vulnerability assessment.

Table 4. Physical parameters pairwise comparison matrix.

\begin{tabular}{|c|c|c|c|c|c|c|c|}
\hline Parameter & $\begin{array}{c}\text { Extreme Flood } \\
\text { Hazard }\end{array}$ & $\begin{array}{l}\text { Hydrographic } \\
\text { Network }\end{array}$ & $\begin{array}{l}\text { Coast } \\
\text { Type }\end{array}$ & $\begin{array}{l}\text { Distance to } \\
\text { Coastline }\end{array}$ & $\begin{array}{c}\text { Solid } \\
\text { Geology }\end{array}$ & $\begin{array}{c}\text { Drift } \\
\text { Geology }\end{array}$ & Land Use \\
\hline Extreme Flood Hazard & 1 & 2 & 3 & 3 & 5 & 7 & 8 \\
\hline $\begin{array}{l}\text { Hydrographic } \\
\text { Network }\end{array}$ & $1 / 2$ & 1 & 2 & 2 & 3 & 5 & 7 \\
\hline Coast Type & $1 / 3$ & $1 / 2$ & 1 & 1 & 3 & 5 & 7 \\
\hline Distance to coastline & $1 / 3$ & $1 / 2$ & 1 & 1 & 3 & 5 & 7 \\
\hline Solid Geology & $1 / 5$ & $1 / 3$ & $1 / 3$ & $1 / 3$ & 1 & 3 & 5 \\
\hline Land Use & $1 / 8$ & $1 / 7$ & $1 / 7$ & $1 / 7$ & $1 / 5$ & $1 / 3$ & 1 \\
\hline Sum & 2.63 & 4.67 & 7.67 & 7.67 & 15.53 & 26.33 & 38.00 \\
\hline
\end{tabular}

Having a comparison matrix (Table 4), a priority vector corresponding to the matrix's normalized eigen vector is computed. This is done by dividing each column element by the corresponding sum (Table 5).

Table 5. Physical parameters normalized matrix.

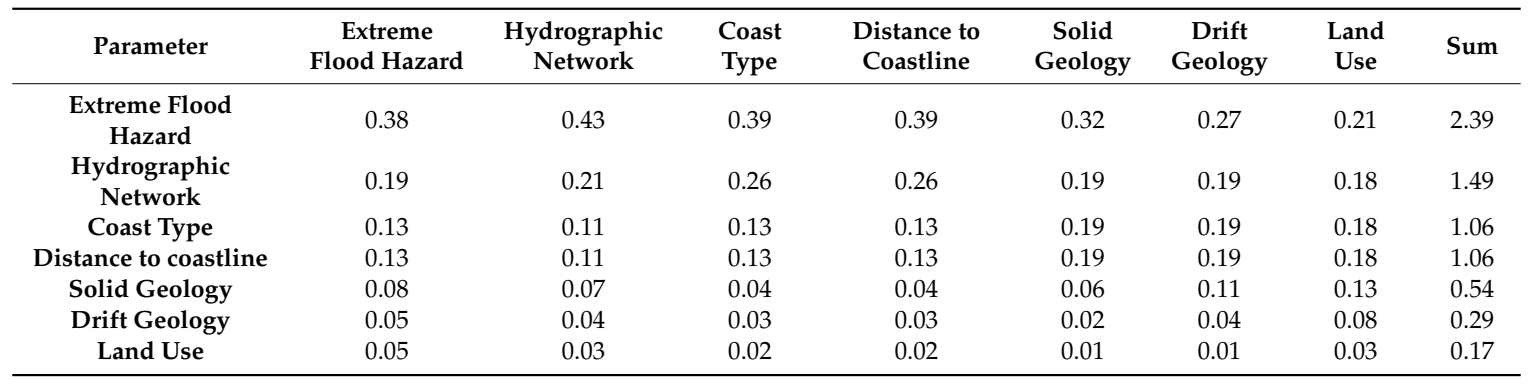

The normalized matrix must be consistent, and thus, a consistency index, known as the consistency ratio (CR), must be computed using Equation (1). If CR satisfies this condition (less than $10 \%$ ), the matrix is consistent; otherwise, the matrix needs to be re-evaluated with different pairwise comparisons and the consistency tested again by the AHP criteria [34].

$$
C R=\frac{C I}{R I}<10 \%
$$

where $C I$ is the consistency index Equation (2) and $R I$ is a random index for different values of $n$. According to [34], for $n=7, R I$ is equal to 1.35 .

$$
C I=\frac{\lambda_{\max }-n}{n-1}
$$

being $\lambda_{\max }$ the sum of the product of each vector by its eigenvalue and $n$ is the matrix order (Table 6 ).

Table 6. Consistency ratio computation (CR).

\begin{tabular}{cccc}
\hline$\lambda_{\max }$ & $n$ & $C I$ & $C R$ \\
\hline 7.42 & 7 & 0.07 & $5.2 \%$ \\
\hline
\end{tabular}


When the CR satisfied the condition imposed by Equation (1), the weights of each physical parameter are determined by dividing the sum of the components and the total number of parameters (Table 7).

Table 7. Matrix for calculating the consistency of relationships between physical vulnerability parameters-a parameter's final weight calculation.

\begin{tabular}{ccc}
\hline Parameter & \multicolumn{2}{c}{ Weight Calculation } \\
\hline Extreme Flood Hazard & $\frac{2.39}{7}$ & $34 \%$ \\
Hydrographic Network & $\frac{1.49}{7}$ & $21 \%$ \\
Coast Type & $\frac{1.06}{7}$ & $15 \%$ \\
Distance to coastline & $\frac{1.06}{7}$ & $15 \%$ \\
Solid Geology & $\underline{0.54}$ & $8 \%$ \\
Drift Geology & $\underline{0.29}$ & $4 \%$ \\
Land Use & $\frac{0.17}{7}$ & $2 \%$ \\
\hline
\end{tabular}

Finally, the Physical Vulnerability Index (PVI) calculation model proposed in this article, which will be applied to each reference year according to the flood models given by each scenario, is presented in Equation (3):

$$
\mathrm{PVI}=\frac{E F H I \times 34 \%+H N \times 21 \%+C T \times 15 \%+D C \times 15 \%+S G * 8 \%+D G * 4 \%+L U * 2 \%}{100 \%}
$$

where EFHI is the extreme flood hazard index proposed by Antunes et al. [33], HN is the hydrographic network distance, $C T$ is the coast type, $D C$ is the coastline distance, $S G$ is the solid geology, $D G$ is the drift geology, and $L U$ is the land use.

According to Equation (3), the most important parameters are the EFHI and the hydrographic network, accounting for $55 \%$, followed by the coast type and coastline distance with $30 \%$. The solid geology and drift geology (erosional susceptibility contribution) weights $12 \%$, while the land-use weights only $2 \%$ of the total parametrization.

\section{Results}

As a result of the PVI determination, it is possible to classify the physical vulnerability of the Portuguese coastal zone by identifying the flooding susceptible areas [33] for future SLR scenarios, 2050 and 2100 [39].

Based on the results of this study, some statistics on the number of people and buildings potentially affected by SLR and extreme events can be determined for the coastal districts of Portugal. The corresponding data of residents and buildings were obtained from the national statistical subsections (census data). Since the census data is from 2011, and SLR is projected to the end of the century, demographic statistical estimates will not represent future reality but only indicators instead. The number of buildings and residents within the vulnerable areas are estimated by district, for each vulnerability class, and for all vulnerable areas, as described in the following sections. The PVI classes were defined and determined using five vulnerability levels (Table 8).

Table 8. Color scheme of the Physical Vulnerability Index results.

\begin{tabular}{cccccc}
\hline Categories & 1-Very Low & 2-Low & 3-Medium & 4-High & 5-Extreme \\
\hline Color Scheme & & & & & \\
\hline
\end{tabular}




\subsection{Physical Coastal Vulnerability Cartography}

\subsubsection{Year 2050}

In the medium-term future (2050 scenario), considering the Mod.FC_2 SLR projection $(44 \mathrm{~cm}$ relative to the Cascais1938 vertical datum [39]) at the high-tide and with a 100-year return period of storm surge, it is estimated that an area of $903.1 \mathrm{~km}^{2}$, comprising a total of 59,530 buildings and 145,550 residents, will be affected by extreme tide flooding and SLR (Table 9). Demographic statistics, as stated above, are based on current values of census data rather than future projections.

Table 9. Physical vulnerability areas (in $\mathrm{km}^{2}$ ) for each class interval and respective number of buildings and residents for the 2050 SLR extreme flood scenario for each coastal district.

\begin{tabular}{|c|c|c|c|c|c|c|c|c|}
\hline \multirow[b]{2}{*}{ District } & \multicolumn{6}{|c|}{ Physical Vulnerability Areas (in km²) $^{2}$} & \multirow{2}{*}{$\begin{array}{l}\text { Number of } \\
\text { Buildings }\end{array}$} & \multirow{2}{*}{$\begin{array}{c}\text { Number of } \\
\text { Residents }\end{array}$} \\
\hline & $\begin{array}{c}1 \\
\text { Very Low }\end{array}$ & $\begin{array}{c}2 \\
\text { Low }\end{array}$ & $\begin{array}{c}3 \\
\text { Medium }\end{array}$ & $\begin{array}{c}4 \\
\text { High }\end{array}$ & $\begin{array}{c}5 \\
\text { Extreme }\end{array}$ & Total & & \\
\hline Aveiro & 0.0 & 0.7 & 12.6 & 55.1 & 103.1 & 171.4 & 11,480 & 26,370 \\
\hline Beja & 0.0 & 0.2 & 1.8 & 4.4 & 0.2 & 6.6 & 830 & 920 \\
\hline Braga & 0.0 & 0.1 & 0.7 & 1.8 & 1.1 & 3.7 & 1260 & 2200 \\
\hline Coimbra & 0.0 & 0.4 & 5.5 & 26.3 & 9.0 & 41.1 & 1570 & 3390 \\
\hline Faro & 0.1 & 2.8 & 12.0 & 65.2 & 102.3 & 182.3 & 18,890 & 36,410 \\
\hline Leiria & 0.2 & 2.4 & 7.1 & 10.0 & 0.6 & 20.2 & 2940 & 3800 \\
\hline Lisbon & 0.0 & 0.5 & 15.6 & 151.8 & 53.5 & 221.4 & 4350 & 16,470 \\
\hline Porto & 0.0 & 0.3 & 0.9 & 1.1 & 0.3 & 2.5 & 3630 & 11,330 \\
\hline Santarém & 0.0 & 0.5 & 16.0 & 55.1 & 27.5 & 99.1 & 1190 & 2150 \\
\hline Setúbal & 0.0 & 4.8 & 17.4 & 93.9 & 20.7 & 136.8 & 11,390 & 38,390 \\
\hline $\begin{array}{l}\text { Viana do } \\
\text { Castelo }\end{array}$ & 0.0 & 1.0 & 4.7 & 8.0 & 4.2 & 17.9 & 2000 & 4120 \\
\hline Total & 0.3 & 13.7 & 94.3 & 472.7 & 322.5 & 903.0 & 59,530 & 145,550 \\
\hline
\end{tabular}

Lisbon is the district with the largest vulnerability area with about $221.4 \mathrm{~km}^{2}$, from which $92.7 \%$ is classified as high and extreme vulnerability. The district of Faro has the highest number of buildings in vulnerable areas, almost 19,000, while Setúbal is the district that has the highest number of residents living (in 2011) in areas vulnerable to SLR, with above 38,000 people.

Figure 9 shows the PVI calculated for ACMP in 2050, focusing on a zone of the Tagus Estuary and an extra zoom map for the military navy base. This military infrastructure is the land-based unit and the main Portuguese Navy installation and operational base. It comprises port infrastructures complex, facilities, and services in Alfeite (left margin) and "Doca de Marinha" (Navy Harbor, right margin), which main functions are the logistic support to the moored units in Lisbon, and the conservation and maintenance of port facilities, infrastructure, and other assigned assets [54]. Such infrastructure, located in a moderate to extreme vulnerability zone, must be adapted to climate change scenarios to maintain its operational function over time.

\subsubsection{Year 2100}

In 2100 (Figure 10), a long-term future (2100) scenario considering the Mod.FC_2 SLR projection (1.15 m relative to the Cascais1938 vertical datum [39]) at the high-tide and with 100-year return period storm surge, it is estimated that an area of $1146 \mathrm{~km}^{2}$, comprising a total of 82,000 buildings and 224,830 residents, will be affected by extreme tide flooding and SLR (Table 10). 


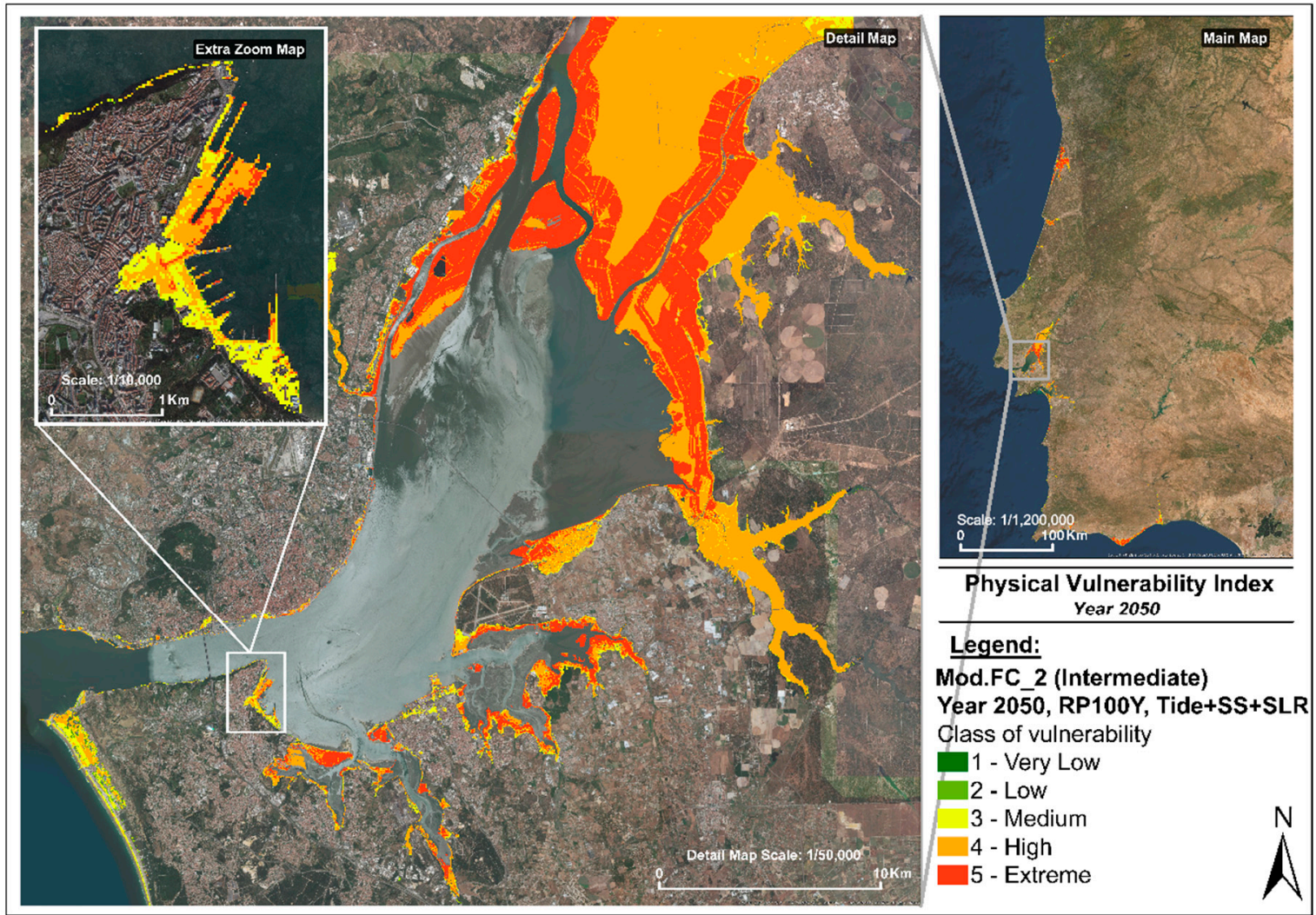

Figure 9. Portuguese coastal physical vulnerability for 2050 SLR and 100-year RP, within a zoom image of the Tagus Estuary and an extra zoom map of the Lisbon Navy Base.

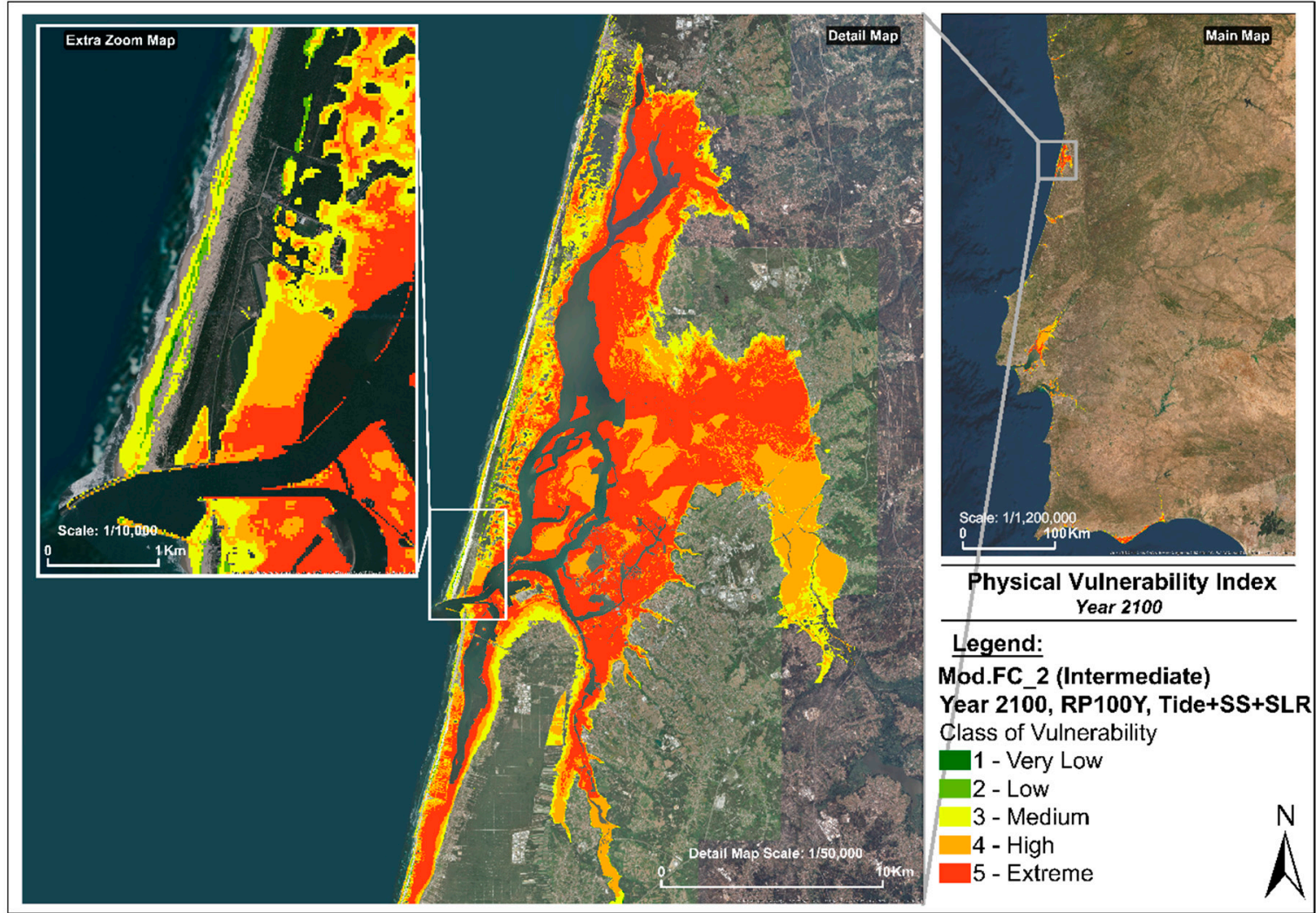

Figure 10. Portuguese coastal physical vulnerability for 2100 SLR and 100-year RP. Zoomed image of the Aveiro inland lagoon. 
Table 10. Physical vulnerability areas (in $\mathrm{km}^{2}$ ) for each class interval and respective number of buildings and residents for the 2100 SLR extreme flood scenario in each coastal district.

\begin{tabular}{|c|c|c|c|c|c|c|c|c|}
\hline \multirow[b]{2}{*}{ District } & \multicolumn{6}{|c|}{ Physical Vulnerability Areas (in $\mathrm{km}^{2}$ ) } & \multirow{2}{*}{$\begin{array}{l}\text { Number of } \\
\text { Buildings }\end{array}$} & \multirow{2}{*}{$\begin{array}{c}\text { Number of } \\
\text { Residents }\end{array}$} \\
\hline & $\begin{array}{c}1 \\
\text { Very Low }\end{array}$ & $\begin{array}{c}2 \\
\text { Low }\end{array}$ & $\begin{array}{c}3 \\
\text { Medium }\end{array}$ & $\begin{array}{c}4 \\
\text { High }\end{array}$ & $\begin{array}{c}5 \\
\text { Extreme }\end{array}$ & Total & & \\
\hline Aveiro & 0.0 & 2.7 & 31.7 & 74.1 & 110.1 & 218.6 & 15,930 & 38,040 \\
\hline Beja & 0.0 & 0.4 & 2.2 & 4.5 & 0.2 & 7.3 & 890 & 960 \\
\hline Braga & 0.0 & 0.2 & 2.9 & 3.0 & 1.6 & 7.6 & 2380 & 4500 \\
\hline Coimbra & 0.1 & 1.8 & 7.6 & 34.5 & 10.0 & 54.0 & 3020 & 6370 \\
\hline Faro & 0.1 & 6.6 & 22.0 & 76.0 & 106.1 & 210.9 & 23,190 & 48,710 \\
\hline Leiria & 0.4 & 4.9 & 13.9 & 14.1 & 0.8 & 34.0 & 3920 & 5540 \\
\hline Lisbon & 0.0 & 1.8 & 16.0 & 174.9 & 56.8 & 249.6 & 6250 & 31,570 \\
\hline Porto & 0.1 & 1.1 & 2.5 & 1.6 & 0.4 & 5.7 & 5430 & 17,140 \\
\hline Santarém & 0.0 & 1.8 & 39.5 & 83.2 & 28.4 & 152.9 & 2150 & 4440 \\
\hline Setúbal & 0.4 & 11.0 & 27.7 & 111.0 & 24.1 & 174.1 & 15,350 & 59,600 \\
\hline $\begin{array}{l}\text { Viana do } \\
\text { Castelo }\end{array}$ & 0.2 & 3.3 & 10.0 & 12.4 & 5.2 & 31.1 & 3490 & 7960 \\
\hline Total & 1.2 & 35.7 & 175.9 & 589.2 & 343.8 & $1,145.8$ & 82,000 & 224,830 \\
\hline
\end{tabular}

For the 2100 scenario, the Lisbon District will again have the largest vulnerability area, $221.4 \mathrm{~km}^{2}$, of which $92.8 \%$ is classified as highly or extremely vulnerable. The district of Faro has the highest number of buildings in areas considered vulnerable, almost 23,190, and the district of Setúbal has the highest number of residents living in areas considered vulnerable to SLR, with around 59,600 people.

It is evident for both scenarios (2050 and 2100) that inland waters are the most affected areas, corresponding also to areas with the highest level of exposure (people and buildings). Districts that have large estuaries will have, in the near future, their area severely affected by SLR and storm surge flood forcing.

This is the case of the Faro and Aveiro districts (Table 10), where the intertidal area will be strongly affected by SLR, increasing, consequently, the vulnerability and the risk caused by a strong urban exposure.

Figures 11-14 show examples of areas containing public and private infrastructures, along the ACMP, classified as moderate to extremely vulnerable areas.
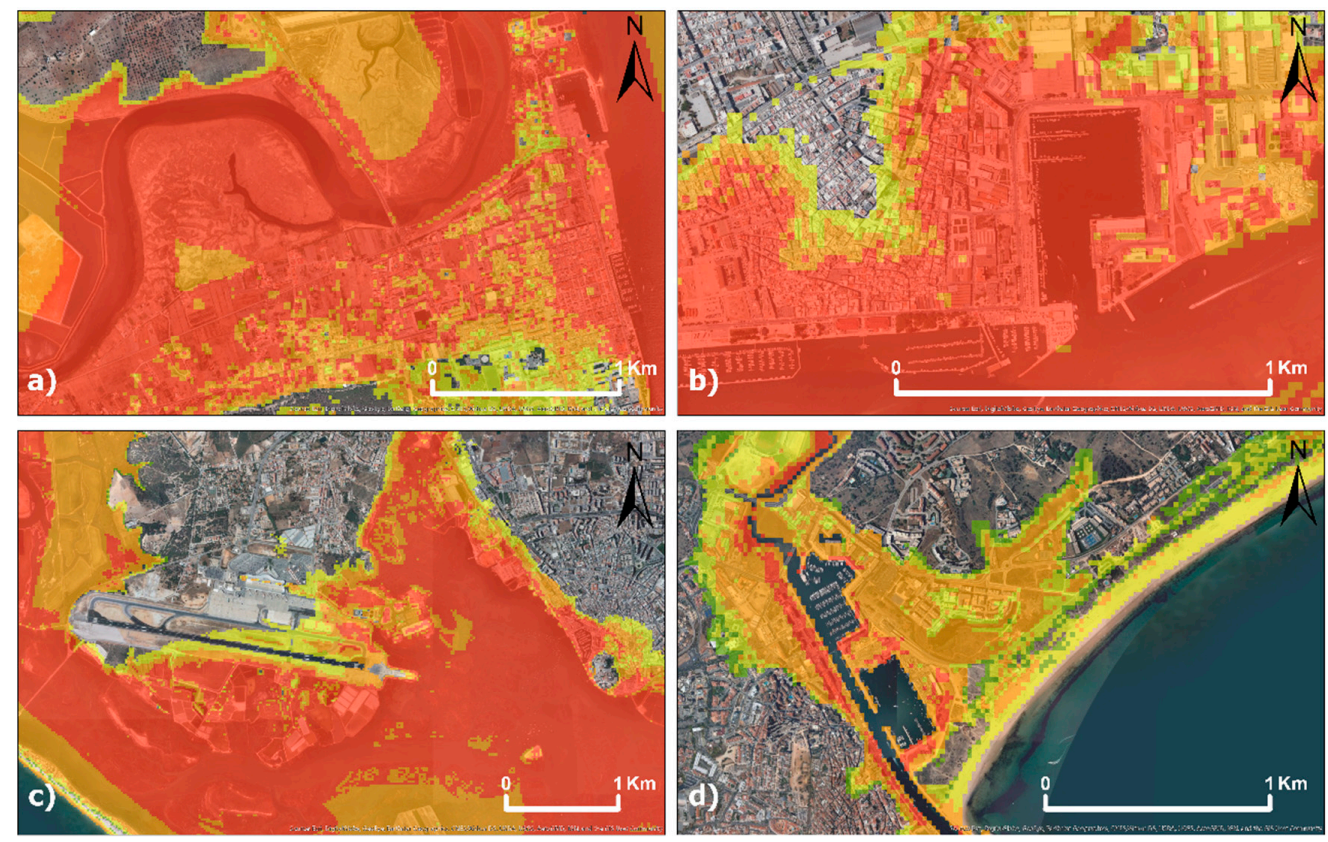

Figure 11. Physical vulnerability for 2100 in the Faro district (Algarve): (a) Vila Real de Santo António city; (b) Olhão city; (c) Faro Airport; (d) Lagos city. 

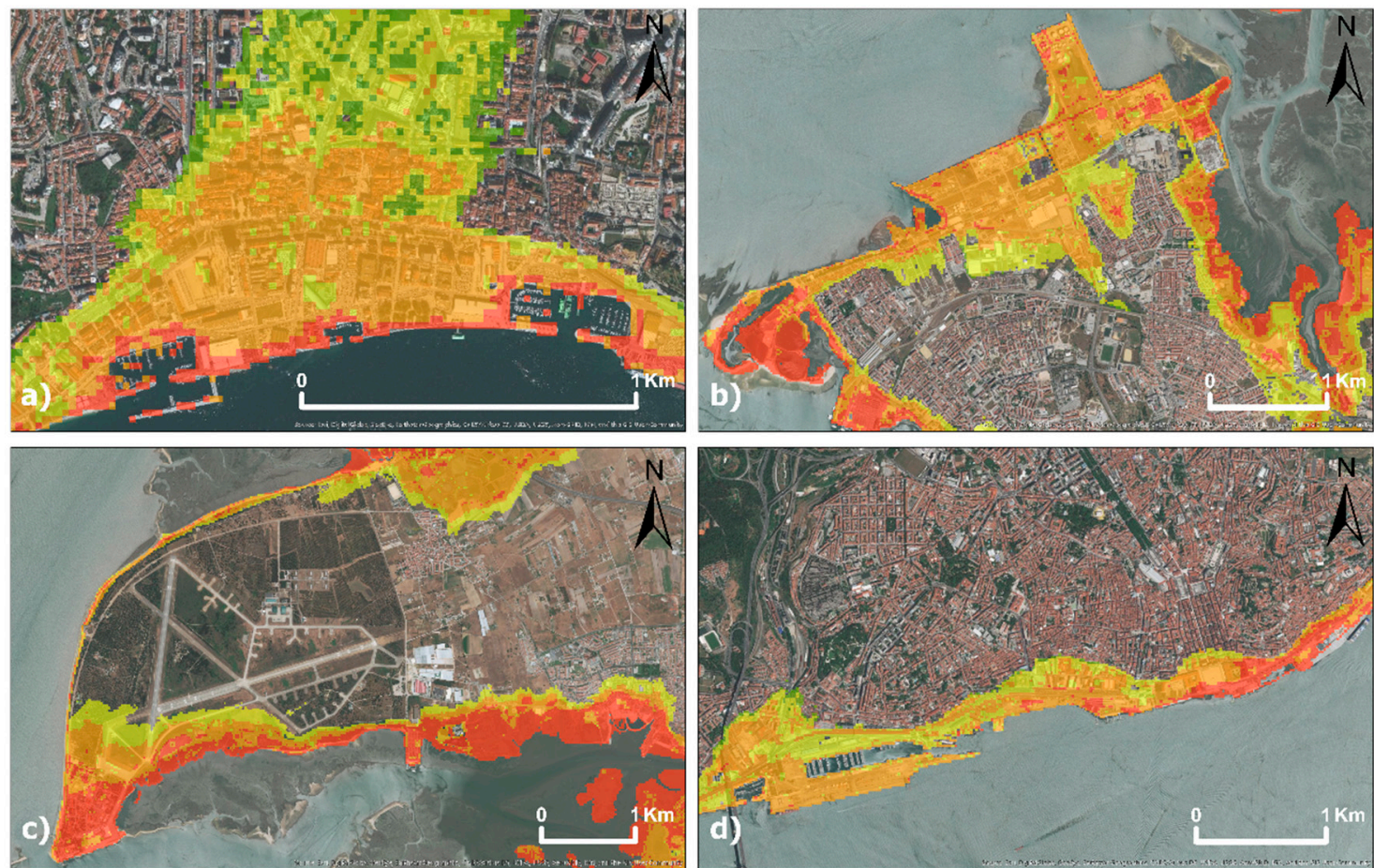

Figure 12. Physical vulnerability for 2100 in the Lisbon Metropolitan Area: (a) Setúbal city; (b) Barreiro city; (c) Montijo Air Base; (d) Lisbon city.
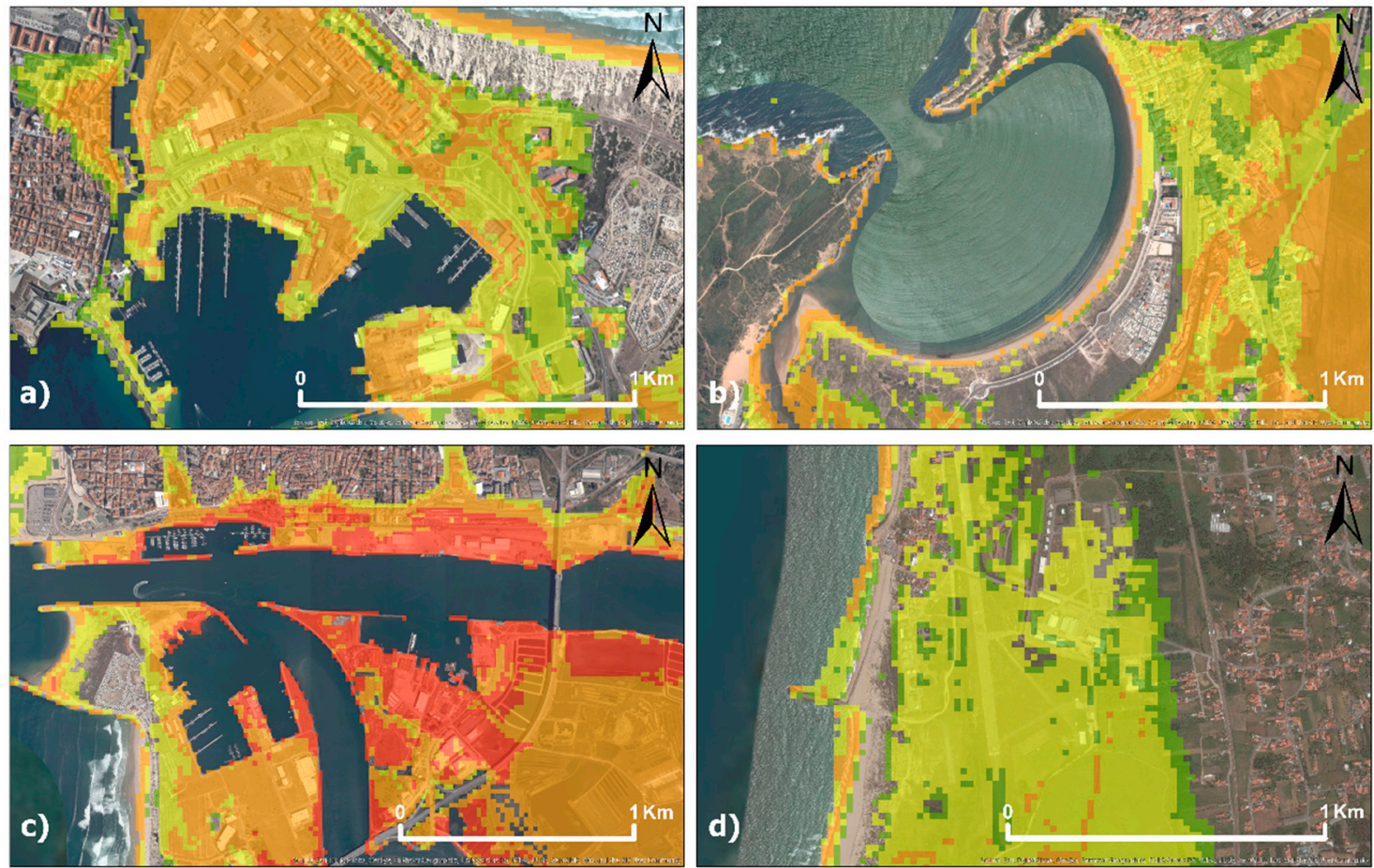

Figure 13. Physical vulnerability for 2100 in Center Region of ACMP: (a) Peniche city; (b) São Martinho do Porto city; (c) Figueira da Foz city; (d) Espinho city. 

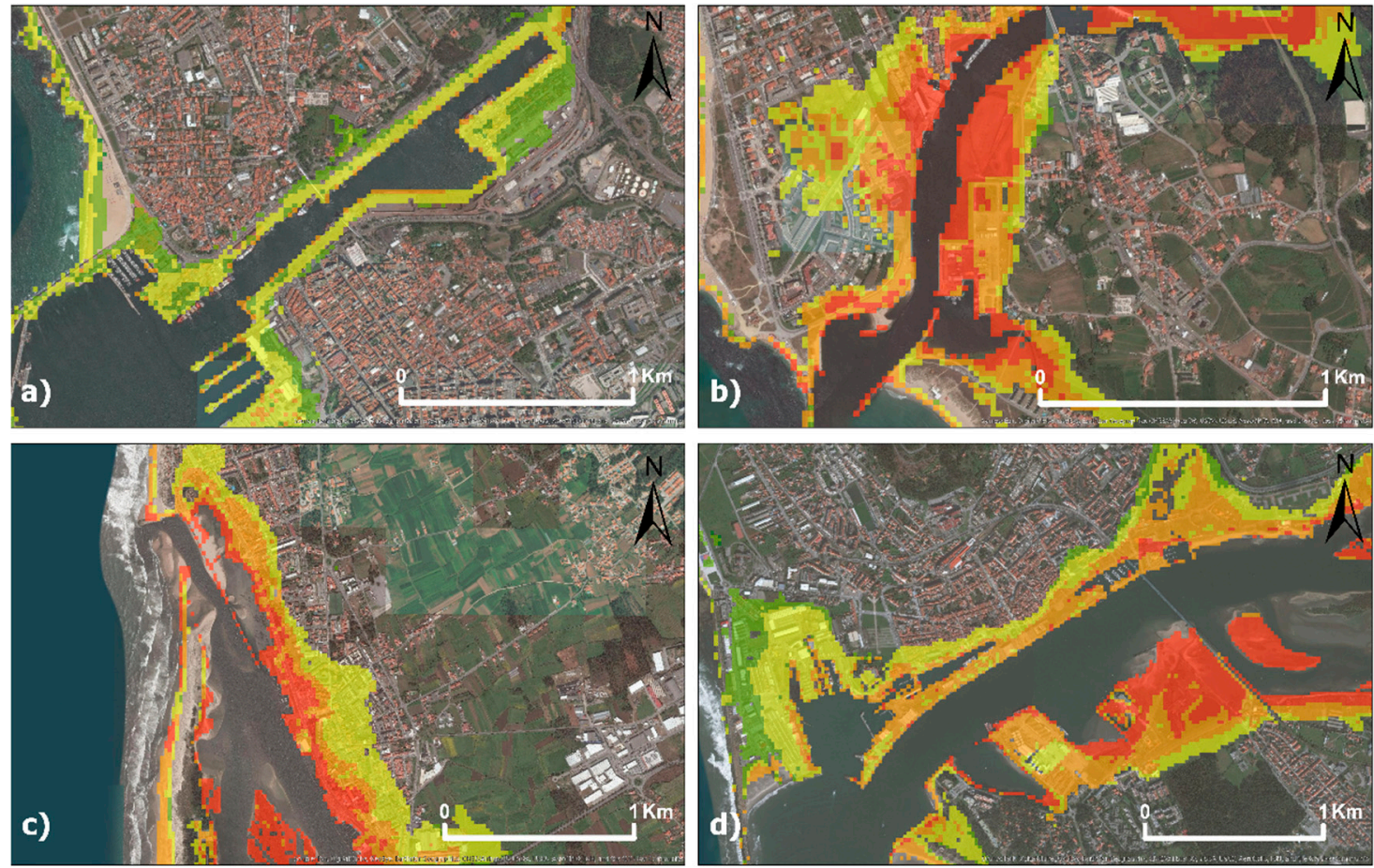

Figure 14. Physical vulnerability for 2100 in North Region of ACMP: (a) Matosinhos city; (b) Vila do Conde city; (c) Esposende city; (d) Viana do Castelo city.

In Figure 11, four cities in the Faro district (south of Portugal) that have important infrastructure in vulnerable zones are highlighted in the final coastal flooding vulnerability maps.

- Figure 11a shows Vila Real de Santo António, the easternmost city of the Faro district, in the Guadiana River mouth. Almost the whole city is at an extreme level of vulnerability with 2700 buildings and 8900 residents in those areas according to Census2011. This is an example of a city where there is an urgent need to define and take SLR adaptation measures.

- The city of Olhão (north of Ria Formosa), in Figure 11b, has its entire downtown classified as an extreme level of vulnerability. Olhão municipality is the most vulnerable to SLR in Algarve since it has the largest number of buildings in areas considered vulnerable; almost 4100 buildings and more than 10,400 people live in those areas.

- Figure 11c shows the Faro International Airport in the Formosa Lagoon system, the main and major infrastructures of the region also being classified in the present assessment as highly to extremely vulnerable.

- Finally, Figure 11d shows Lagos city, where the Lagos Marina is partially classified as highly and extremely vulnerable. On the western side of the river, numerous infrastructures ( 1600 buildings) are in vulnerable areas, such as gas stations, a hospital, a bus station, a church.

Figure 12 shows four cities in the Lisbon Metropolitan Area that contain important infrastructures in vulnerable zones:

- In Figure 12a, the downtown of the Setúbal city is classified as highly to extremely vulnerable. The Setúbal municipality is the second most vulnerable in the district, with a high number of buildings in areas considered vulnerable, almost 3000 buildings and more than 12,000 residents.

- In the case of the Barreiro city (Figure 12b), with strong urban exposure on the left margin of the Tagus estuary, there are almost 1600 buildings and 9700 residents in areas considered vulnerable.

- Figure 12c shows the Montijo Air Base (BA6), which belongs to the Portuguese Air Force, and where a second airport complementary to the Lisbon hub airport is projected. 
- The last figure (Figure 12d) shows Lisbon city is one of the most vulnerable cities in the country. These result not only from the considerable number of buildings and people living in these areas ( $\sim 1600$ and 13,500, respectively) but also from the value of the buildings and other infrastructures present in the right margin of the Tagus estuary. This margin will be severely affected, and as a result, numerous infrastructures that already exist or are designated for future construction within the area will be at risk. Facing this problem, the Lisbon municipality has already begun to make relocation plans, imposing some restrictions for new constructions in its Municipal Director Plan. However, more serious actions will have to be taken since numerous heritage and national interest buildings, as well as important infrastructures, are located in areas of high to extreme vulnerability, such as the case of train tracks, metro stations, museums, gas stations, cruise terminal, marinas and harbors, some buildings on Praça do Comércio, the Cais do Sodré train station and fluvial station, among others.

In Figure 13 are presented four examples of cities in the ACPM Center Region that also contain important infrastructure in vulnerable zones:

- In Figure 13a is the Peniche Peninsula; the downtown of the city is practically classified as medium to highly vulnerable, having 834 buildings and 2072 residents in those areas.

- The municipality of Alcobaça (Figure 13b) is also one of the most vulnerable to SLR, accounting for 1494 buildings and 1428 residents in vulnerable areas. Figure 13b shows the parish of São Martinho do Porto, which despite being around a protected bay, may have in 2100 some of its infrastructure at risk, such as a police station, the train line, a health center.

- In the case of Figueira da Foz (Figure 13c), with a strong urban exposure near to the Mondego river, there are almost 1997 buildings and 4849 residents in areas considered vulnerable.

- In the Espinho municipality, 276 buildings and 747 residents are in vulnerable areas. Figure $13 \mathrm{~d}$ shows the Engineering Regiment No. 3 (RE3), which is a military unit of the Portuguese Army located at the Paramos headquarters. This is another military facility that is located in an SLR vulnerable zone.

In Figure 14 it is possible to see four examples in the ACMP North Region:

- The Matosinhos city is illustrated in Figure 14a, and is the second most vulnerable in the Porto district, with a high number of buildings in areas considered vulnerable, almost 830 buildings (including the port administration), and more than 2300 residents.

- The Vila do Conde municipality in Figure $14 \mathrm{~b}$ is the most vulnerable to SLR in the Porto district, with the highest number of buildings in areas considered vulnerable, almost 1470 buildings and more than 5000 people living actually in those areas. Thus, it is important that the Vila do Conde municipality take quick SLR adaptation and mitigation measures.

- In Figure 14c, the Esposende city is the most vulnerable in the Braga district, with a strong urban pressure near the Cávado river, with almost 2250 buildings and 4000 residents in the areas considered as vulnerable.

- Finally, Figure $14 \mathrm{~d}$ shows Viana do Castelo, the district capital. One can observe on the Lima riverbank side, several zones classified as highly to extremely vulnerable, with 1466 buildings and 4236 residents.

\subsection{Web-Viewer: Sea Level Rise for Portugal}

All the products that resulted from this study are available to the Portuguese public entities as WMS and through a web viewer for the civil community and public in general [55]. The purpose of this Web Viewer is the dissemination of the present study's results.

The website has three main tabs, one providing a preliminary look at SLR and coastal flooding impacts, allowing users to visualize the impact of extreme flooding for each future SLR scenario (2025, 2050, and 2100) and compare the different scenarios (Figure 15a). The same structure is available, 
on a second tab, for the physical vulnerability of different scenarios (Figure 15b) or unique scenario (Figure 15c). Finally, some demographic statistics are provided for vulnerable areas in a third tab, particularly the number of houses and the number of residents per district and municipality affected in each scenario, considering the Census2011 data (Figure 15d).
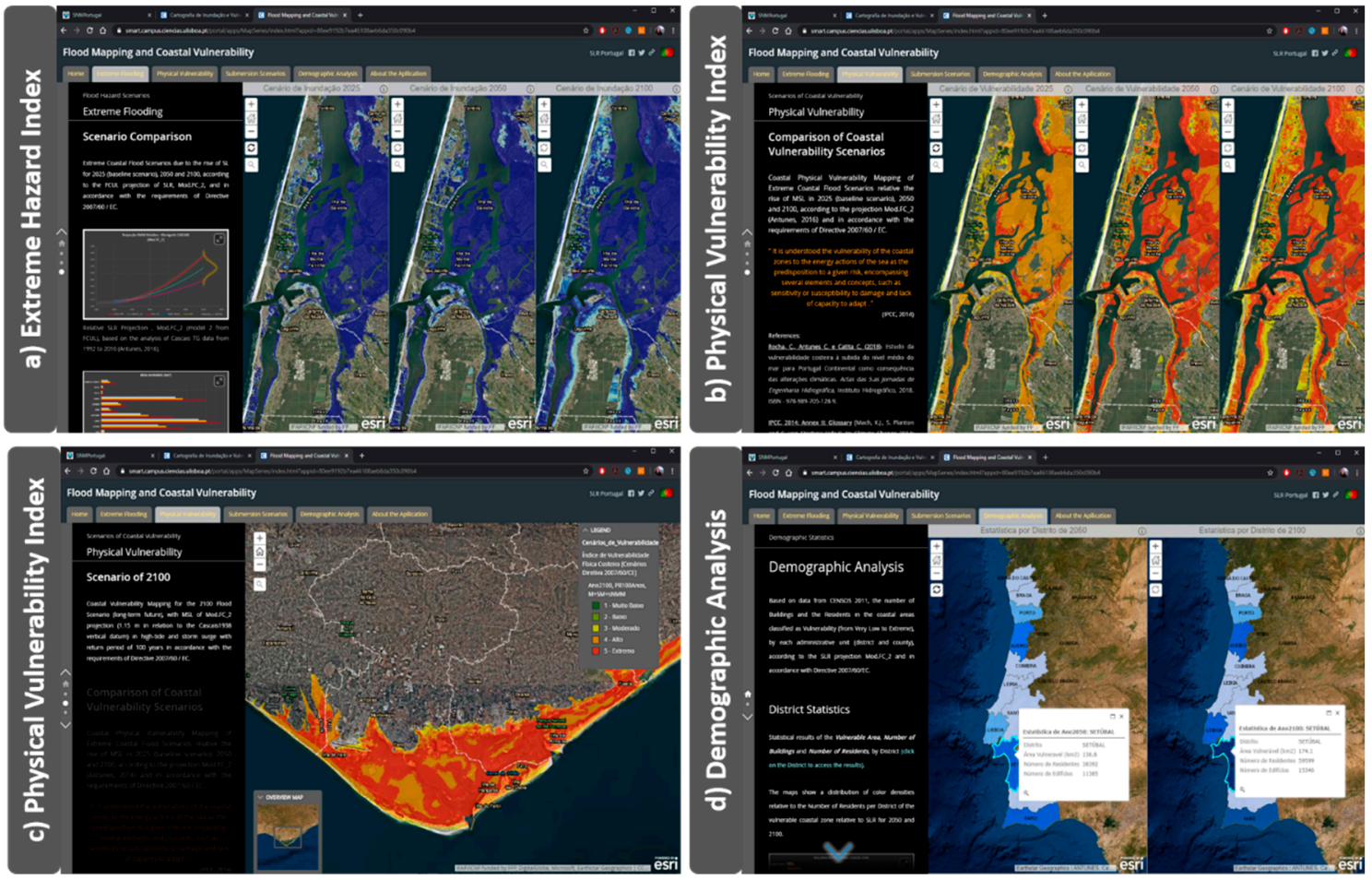

Figure 15. The SNMPortugal Website [55] created to disseminate the results of this study. (a) Examples of Extreme Flood Hazard Index for 2025, 2050, and 2100 in the Aveiro Lagoon; (b) Physical Vulnerability Index for all temporal scenarios, also for the Aveiro Lagoon; (c) Physical Vulnerability Index for the Formosa Lagoon in 2100; and (d) some demographic statistics that can be accessed per district or municipality, selecting the corresponding polygon.

The maps available at the web viewer are provided "as they are", without any warranty of their performance, merchantable state, or fitness for any particular purpose. This tool should be strictly used as a navigation tool and not for legal purposes.

\section{Discussion and Conclusions}

The present study defines a methodology to characterize, identify, and quantify the affected ACMP areas vulnerable to coastal flooding in 2050 and 2100, with different extreme flooding scenarios based on SLR projections and extreme events with different return periods. For this purpose, a coastal Physical Vulnerability Index was defined and determined at a national scale.

Areas where the PVI class values are higher, and consequently most affected by SLR and extreme events, are areas associated with high anthropogenic pressure. In 2050, considering the Mod.FC_2 SLR projection with $44 \mathrm{~cm}$ relative to the national vertical datum [39], an ACMP vulnerable area of $903.1 \mathrm{~km}^{2}$ was calculated. In addition, this study shows that several infrastructures in those vulnerable areas, containing a total of 59,530 buildings and 145,550 residents, are at risk due to SLR. The Lisbon district was also identified as the most susceptible district to SLR impact, with a vulnerable area of around $221.4 \mathrm{~km}^{2}, 92.7 \%$ of which is classified as highly and/or extremely vulnerable. In a long-term future (2100), considering the Mod.FC_2 SLR projection with a $1.15 \mathrm{~m}$ rise relative to the national vertical datum [39] at the high-tide and with 100 years return period storm surge, the estimated vulnerable area for Lisbon district is about $1146 \mathrm{~km}^{2}$, comprising a total of 82,000 buildings and 224,830 residents. 
This study also proves that the quality of the results is highly dependent on data quality. Access to reliable data was one of the most challenging factors throughout the study since the available free data have low positional accuracy and detail due to the scale of the products that are made available to the public through the websites. In these circumstances, it is necessary to apply numerous transformation/digitalization processes in order to make the usable data viable (e.g., as it was done for the hydrographic network).

Despite these limitations, the national DTM used to calculate the EFHI, validated on 134 national geodetic marks [33], proved to be sufficiently accurate to retrieve the results at a national scale with a spatial resolution of $20 \mathrm{~m}$. For comparison and gross validation, the demographic statistics were compared with the results obtained by Kulp and Strauss [56], which used a new global Coastal DEM (digital elevation model, different from a DTM), not validated for Portugal, with a spatial resolution of $30 \mathrm{~m}$. Table 11 shows significant differences between both studies in the estimated number of people affected in Portugal in 2050 and 2100. Comparing Kulp and Strauss [56] results with SLR projections of Koop et al. [57] (RCP 4.5-DP16) for 2050, which also corresponds to the 99th percentile of Antunes [39] used in this study, a total of around 80,000 people living on coastal flood areas will be affected by SLR. These values correspond to less than $45 \%$ than those obtained in the present study for 2050, while for 2100 , Kulp and Strauss [56] estimated a total of $\sim 140,000$ people affected, corresponding to less than $62 \%$ in comparison with the present results.

Table 11. Comparison of results for the affected population for Portugal in 2050 and 2100 presented in [56], with the results obtained in the present study.

\begin{tabular}{lcccc}
\hline \multicolumn{1}{c}{ Projections } & GMSL (m) & $\begin{array}{c}2050 \\
\text { Population } \\
\text { Estimated }\end{array}$ & GMSL (m) & $\begin{array}{c}\text { Population } \\
\text { Estimated }\end{array}$ \\
\hline RCP4.5-ModFC_2 & $0.11-0.51[39]$ & 145,550 & $0.10-1.80[39]$ & 224,830 \\
RCP4.5-K14 & $0.15-0.41[57]$ & $N / D$ & $0.26-1.28[57]$ & $100,000[56]$ \\
RCP8.5-K14 & $0.17-0.46[57]$ & $80,000[56]$ & $0.40-1.59[57]$ & $120,000[56]$ \\
RCP4.5-DP16 & $0.10-0.52[57]$ & $80,000[56]$ & $0.39-1.80[57]$ & $140,000[56]$ \\
\hline
\end{tabular}

$\mathrm{RCP}=$ representative concentration pathway; GMSL = projections of global-mean sea-level; ModFC_2 = Antunes [39] projection for Portugal; K14 = sea-level model employs a probabilistic approach and includes very little contribution from Antarctica in its central projections [57]; DP16 = sea-level model links physical models of ice sheet loss to the projection framework established in K14, thus emphasizing the possibility of early-onset Antarctic instability [57]. $\mathrm{N} / \mathrm{D}=$ The study [56] does not show the affected population for this projection.

In short, the methodological approach is simple, robust, and easy to implement since it is based on well-defined criteria through an index-normalized formulation and additional parameters can be included with different weights determined consistently with the AHP method. Although further improvements in the methodology are required to assess coastal risk for SLR mitigation and adaptation measures, the present results are an important contribution to the identification of coastal vulnerability, constituting an additional instrument for decision-makers with responsibilities of management and planning of areas exposed to the sea energy actions.

One has to keep in mind that if the $2{ }^{\circ} \mathrm{C}$ climate change mitigation target fails, the global annual flood costs, without adaptation, are projected to be USD 14.3 trillion per year, which account for $2.5 \%$ of GDP for the median SLR scenario RCP8.5_J14 $(0.86 \mathrm{~m})$, and up to USD 27.0 trillion per year for the respective 95th percentile $(1.80 \mathrm{~m})$, accounting for $4.7 \%$ of global GDP according to Jevrejeva et al. [58]. Considering Portugal as part of the upper middle-income countries and, according to Jevrejeva et al. [58], without any adaptation efforts, the coastal flooding from RCP8.5_J14 SLR at the end of the 21st century may correspond to an annual national GDP cost up to $7.2 \%$. Alternatively, with adaptation efforts, national GDP costs might come down to just $0.3 \%$. Such potential costs related to coastal flooding reinforce the importance of the present work, which contributes to an improved coastal risk assessment, allowing the design and implementation of coastal flooding adaptation measures. 
The lack of a vulnerability assessment disables the implementation of timely adaptation measures, which lead to a negative economic impact since substantial flooding costs are not avoided.

Future detailed and more specific analysis will have to be carried out at a local scale for each area identified in this study as highly and/or extremely vulnerable, as defined in Directive 207/60/CE. Therefore, some perspectives of future work may be raised from this study: (a) Apply and test the methodology using a DTM with an improved spatial resolution; (b) apply socioeconomic vulnerability to exposure models for highly vulnerable areas, creating a multi-scale approach for risk assessment; (c) implement shoreline retreat/accretion rates, or morphodynamical evolution modeling to the physical vulnerability local scale model; (d) incorporate LiDAR data into nearshore bathymetry, enabling the incorporation of beach slopes, required for the total runup estimation as well as the location of coastal protection structures into local vulnerability models; and (e) develop and strengthen cooperation with coastal management decision makers to produce all the background information required for this type of study.

Author Contributions: Conceptualization, C.R., C.A. and C.C.; Methodology, C.R., C.A. and C.C.; Software, C.R.; Validation, C.R. and C.A; Formal Analysis, C.R., C.A. and C.C.; Investigation, C.R. and C.A.; Resources, C.A. and C.C.; Supervision: C.A.; Data Curation, C.R.; Writing-original draft preparation, C.R. and C.A.; Writing-review and editing, C.R., C.A. and C.C.; Visualization, C.R. All authors have read and agreed to the published version of the manuscript.

Funding: The authors would like to acknowledge the financial support FCT through project UIDB/50019/2020 - IDL.

Conflicts of Interest: The authors declare no conflict of interest.

\section{References}

1. IPCC, 2018: Summary for Policymakers. In Global Warming of $1.5^{\circ} \mathrm{C}$. An IPCC Special Report on the Impacts of Global Warming of $1.5^{\circ} \mathrm{C}$ above Pre-Industrial Levels and Related Global Greenhouse Gas Emission Pathways, in the Context of Strengthening the Global Response to the Threat of Climate Change, Sustainable Development, and Efforts to Eradicate Poverty; Masson-Delmotte, V., Zhai, P., Pörtner, H.-O., Roberts, D., Skea, J., Shukla, P.R., Pirani, A., Moufouma-Okia, W., Péan, C., Pidcock, R., et al., Eds.; World Meteorological Organization: Geneva, Switzerland, 2018; p. 32.

2. IOC/UNESCO, IMO, FAO, UNDP. A Blueprint for Ocean and Coastal Sustainability. An Inter-Agency Report towards the Preparation of the UN Conference on Sustainable Development (Rio+20). Available online: https: //digital.library.unt.edu/ark:/67531/metadc226586/m2/1/high_res_d/UNDP\%20-\%20Rio\%20+20.pdf (accessed on 28 January 2020).

3. ESTAT. Nearly Half of the Population of EU Countries with a Sea Border Is Located in Coastal Regions. Statistics in Focus. Available online: https:/ec.europa.eu/eurostat/documents/3433488/5281405/KS-SF-09047-EN.PDF/121dae7c-a53c-464a-baca-a314e652f4e7 (accessed on 28 January 2020).

4. EEA. The Changing Faces of Europe's Coastal Areas; EEA Report; European Environment Agency; Copenhagen, Denmark. Available online: https://www.eea.europa.eu/publications/eea_report_2006_6 (accessed on 28 Jaunuary 2020).

5. McGranahan, G.; Balk, D.; Anderson, B. The rising tide: Assessing the risks of climate change and human settlements in low elevation coastal zones. Environ. Urbaniz. 2007, 19, 17-37. [CrossRef]

6. IPCC, 2014: Climate Change 2014: Impacts, Adaptation, and Vulnerability. In Part A: Global and Sectoral Aspects. Contribution of Working Group II to the Fifth Assessment Report of the Intergovernmental Panel on Climate Change; Field, C.B.; Barros, V.R.; Dokken, D.J.; Mach, K.J.; Mastrandrea, M.D.; Bilir, T.E.; Chatterjee, M.; Ebi, K.L.; Estrada, Y.O.; Genova, R.C.; et al. (Eds.) Cambridge University Press: Cambridge, UK; New York, NY, USA; p. 1132.

7. Neumann, B.; Vafeidis, A.T.; Zimmermann, J.; Nicholls, R.J. Future coastal population growth and exposure to sea-level rise and coastal flooding-a global assessment. PLoS ONE 2015, 10, e0118571. [CrossRef] [PubMed]

8. European Parliament; Council of the European Union. Floods Directive (2007/60/EC); European Environment Agency: Copenhagen, Denmark, 2007; Volume 50-L288, pp. 27-34. 
9. SINIAmb—Sistema Nacional de Informação de Ambiente. Available online: https://sniamb.apambiente.pt/ (accessed on 24 July 2016).

10. Mach, K.J.; Planton, S.; von Stechow, C. Annex II: Glossary. In Climate Change 2014: Synthesis Report. Contribution of Working Groups I, II and III to the Fifth Assessment Report of the Intergovernmental Panel on Climate Change; Core Writing Team, Pachauri, R.K., Meyer, L.A., Eds.; IPCC: Geneva, Switzerland, 2014; pp. 117-130.

11. Gornitz, V.M.; White, T.W.; Cushman, R.M. Vulnerability of the U.S to future Sea Level Rise. J. Coast. Res. 1991, 9, 201-237.

12. Gornitz, V.; Daniels, R.C.; White, T.W.; Birdwell, K.R. The development of a coastal risk assessment database: Vulnerability to sea-level rise in the U.S. Southeast. J. Coast. Res. 1994, 12, 327-338.

13. Shaw, J.; Taylor, R.B.; Forbes, D.L.; Ruz, M.-H.; Solomon, S. Sensitivity of the coasts of Canada to sea-level rise. In Geological Survey of Canada Bulletin 505; Geological Survey of Canada: Ottawa, ON, Canada, 1998; p. 90.

14. Thieler, E.R.; Hammar-Klose, E.S. National Assessment of Coastal Vulnerability to Sea-Level Rise: Preliminary Results for the U.S. Atlantic Coast; U.S. Geological Survey Open-File Report 99-593; U.S. Geological Survey: Woods Hole, MA, USA, 1999.

15. Pendleton, E.A.; Thieler, E.R.; Williams, S.J. Coastal Vulnerability Assessment of Cape Hatteras National Seashore (CAHA) to Sea-Level Rise; U.S. Geological Survey Open-File Report 2004-1064; U.S. Geological Survey: Woods Hole, MA, USA, 2005.

16. Boruff, B.J.; Emrich, C.; Cutter, S.L. Erosion Hazard Vulnerability of US Coastal Counties. J. Coast. Res. 2005, 21, 932-942. [CrossRef]

17. Doukakis, E. Coastal Vulnerability and Risk Parameters. Eur. Water 2005, 11/12, 3-7.

18. Diez, P.G.; Perillo, G.M.; Piccolo, M.C. Vulnerability to Sea-Level Rise on the Coast of the Buenos Aires Province. J. Coast. Res. 2007, 231, 119-126. [CrossRef]

19. Rao, K.N.; Subraelu, P.; Rao, T.V.; Malini, B.H.; Ratheesh, R.; Bhattacharya, S.; Rajawat, A.S.; Ajai. Sea-level rise and coastal vulnerability: An assessment of Andhra Pradesh coast, India through remote sensing and GIS. J. Coast. Conserv. 2008, 12, 195-207.

20. Abuodha, P.A.; Woodroffe, C.D. Assessing vulnerability to sea-level rise using a coastal sensitivity index: A case study from southeast Australia. J. Coast. Conserv. 2010, 14, 189-205. [CrossRef]

21. Bagdanavičiūtè, I.; Kelpšaitè, L.; Soomere, T. Multi-criteria evaluation approach to coastal vulnerability index development in micro-tidal low-lying areas. Ocean Coast. Manag. 2015, 104, 124-135. [CrossRef]

22. Serio, F.; Armenio, E.; Mossa, M.; Petrillo, A.F. How to Define Priorities in Coastal Vulnerability Assessment. Geosciences 2018, 8, 415. [CrossRef]

23. Zhu, Z.-T.; Cai, F.; Chen, S.-L.; Gu, D.-Q.; Feng, A.-P.; Cao, C.; Qi, H.-S.; Lei, G. Coastal Vulnerability to Erosion Using a Multi-Criteria Index: A Case Study of the Xiamen Coast. Sustainability 2018, 11, 93. [CrossRef]

24. Ružić, I.; Jovančević, S.D.; Benac, Č.; Krvavica, N. Assessment of the Coastal Vulnerability Index in an Area of Complex Geological Conditions on the Krk Island, Northeast Adriatic Sea. Geosciences 2019, 9, 219. [CrossRef]

25. Koroglu, A.; Ranasinghe, R.; Jiménez, J.A.; Dastgheib, A. Comparison of Coastal Vulnerability Index applications for Barcelona Province. Ocean Coast. Manag. 2019, 178, 104799. [CrossRef]

26. Mahmood, R.; Ahmed, N.; Zhang, L.; Li, G. Coastal vulnerability assessment of Meghna estuary of Bangladesh using integrated geospatial techniques. Int. J. Disaster Risk Red. 2019, 42, 101374. [CrossRef]

27. Coelho, C. Riscos de Exposição de Frentes Urbanas para Diferentes Intervenções de Defesa Costeira. Ph.D. Thesis, University of Aveiro, Aveiro, Portugal, 2005.

28. Coelho, C.; Silva, R.; Veloso-Gomes, F.; Pinto, F.T. A vulnerability analysis approach for the Portuguese West Coast. WIT Trans. Ecol. Environ. 2006, 91, 251-262.

29. Pereira, C.; Coelho, C. Coastal risk maps due to waves actions. J. Integr. Coast. Zone Manag. 2013, 13, $27-43$.

30. Ceia, F.R.; Patrício, J.; Marques, J.C.; Dias, J.A. Coastal vulnerability in barrier islands: The high risk areas of the Ria Formosa (Portugal) system. Ocean Coast. Manag. 2010, 53, 478-486. [CrossRef]

31. Martins, V.N.; Pires, R.; Cabral, P. Modelling of coastal vulnerability in the stretch between the beaches of Porto de Mós and Falésia, Algarve (Portugal). J. Coast. Conserv. 2012, 16, 503-510. [CrossRef]

32. Martínez-Graña, A.M.; Boski, T.; Goy, J.L.; Dabrio, C.J. Coastal-flood risk management in central Algarve: Vulnerability andflood risk indices (South Portugal). Ecol. Indic. 2016, 71, 302-316. [CrossRef]

33. Antunes, C.; Rocha, C.; Catita, C. Coastal Flood Assessment due to Sea Level Rise and Extreme Storm Events: A Case Study of the Atlantic Coast of Portugal's Mainland. Geosciences 2019, 9, 239. [CrossRef] 
34. Saaty, R.W. The Analytic Hierarchy Process - What it is and how it is used. Math Model. 1987, 9, 161-176. [CrossRef]

35. Instituto Hidrográfico. Roteiro da Costa de Portugal Continental - do Cabo Carvoeiro ao Cabo de São Vicente, 3rd ed.; Instituto Hidrográfico: Lisboa, Portugal, 2006; p. 462.

36. Andrade, C.; Pires, H.; Silva, P.; Taborda, R.; Freitas, M.C. Zonas Costeiras. In Alterações Climáticas em Portugal. Cenários, Impactos e Medidas de Adaptação—SIAM II"; Santos, F.D., Miranda, P., Eds.; Gradiva: Lisboa, Portugal, 2006; pp. 169-206.

37. Andrade, C.; Freitas, M.C.; Cachado, C.; Cardoso, A.C.; Monteiro, J.H.; Brito, P.; Rebelo, L. Coastal Zones. In Climate Change in Portugal. Scenarios, Impacts and Adaptation Measures-SIAM Project; Santos, F.D., Forbes, K., Moita, R., Eds.; Gradiva: Lisboa, Portugal, 2002; pp. 175-219.

38. McLaughlin, S.; Cooper, J.A.G. A multi-scale coastal vulnerability index: A tool for coastal managers? Environ. Hazards 2010, 9, 233-248. [CrossRef]

39. Antunes, C. Assessment of Sea Level Rise at West Coast of Portugal Mainland and Its Projection for the 21st Century. J. Mar. Sci. Eng. 2019, 7, 61. [CrossRef]

40. Soares da Silva, A.M. Carta Litológica-Notícia Explicativa I.13; Comissão Nacional do Ambiente: Lisboa, Portugal, 1983; p. 21.

41. IGP. Carta de Uso e Ocupação do Solo de Portugal Continental para 2007-Memória descritiva; Instituto Geográfico Português: Lisbon, Portugal, 2010; p. 87.

42. Ayalew, L.; Yamagishi, H.; Marui, H.; Kanno, T. Landslides in Sado Island of Japan: Part II. GIS-based susceptibility mapping with comparisons of results from two methods and verifications. Eng Geol. 2005, 81, 432-445. [CrossRef]

43. Gorsevski, P.; Gessler, P.; Boll, J.; Elliot, W.; Foltz, R. Spatially and temporally distributed modeling for landslide susceptibility. Geomorphology 2006, 80, 178-198. [CrossRef]

44. Yacin, A. GIS-based landside susceptibility mapping using analytical hierarchy process and bivariate statistics in Ardesen (Turkey): Comparisons of results and confirmations. Catena 2008, 72, 1-12. [CrossRef]

45. Ercanoglu, M.; Kasmer, O.; Temiz, N. Adaptation and comparison of expert opinion to analytical hierarchy process for landslide susceptibility mapping. Bull. Eng. Geol. Environ. 2008, 67, 565-578. [CrossRef]

46. Pal, I.; Nath, S.; Shukla, K.; Pal, D.; Raj, A.; Thingbaijam, K.; Bansal, B. Earthquake hazard zonation of Sikkim Himalaya using a GIS platform. Nat. Hazards 2008, 45, 333-377. [CrossRef]

47. Dang, N.; Babel, M.; Luong, H. Evaluation of flood risk parameters in the Day River Flood Diversion Area, Red River Delta, Vietnam. Nat. Hazards 2011, 56, 169-194. [CrossRef]

48. Chen, Y.R.; Yeh, C.H.; Yu, B. Integrated application of the analytic hierarchy process and the geographic information system for flood risk assessment and flood plain management in Taiwan. Nat. Hazards 2011, 59, 1261-1276. [CrossRef]

49. Chang, H.-K.; Liou, J.-C.; Chen, W.-W. Protection Priority in the Coastal Environment Using a Hybrid AHP-TOPSIS Method on the Miaoli Coast, Taiwan. J. Coast. Res. 2012, 28, 369-374. [CrossRef]

50. Yin, J.; Yin, Z.; Wang, J.; Xu, S. National assessment of coastal vulnerability to sea-level rise for the Chinese coast. J. Coast. Conserv. 2012, 16, 123-133. [CrossRef]

51. Le Cozannet, G.; Garcin, M.; Bulteau, T.; Mirgon, C.; Yates, M.L.; Méndez, M.; Baills, A.; Idier, D.; Oliveros, C. An AHP-derived method for mapping the physical vulnerability of coastal areas at regional scales. Nat. Hazards Earth Syst. Sci. 2013, 13, 1209-1227. [CrossRef]

52. Murali, R.; Ankita, M.; Amrita, S.; Vethamony, P. Coastal Vulnerability assessment of Puducherry coast, India, using the analytical hierarchy process. Nat. Hazards Earth Syst. Sci. 2013, 13, 3291-3311. [CrossRef]

53. Sekovski, I.; Río, L.; Armaroli, C. Development of a coastal vulnerability index using analytical hierarchy process and application to Ravenna province (Italy). Ocean Coast. Manag. 2019, 183, 104982. [CrossRef]

54. Portuguese Navy. Available online: https://www.marinha.pt/pt/os_meios/bases/Paginas/BNL.aspx (accessed on 22 November 2019).

55. Antunes, C.; Rocha, C.; Catita, C. Sea Level Rise for Portugal. Available online: http://www.snmportugal.pt (accessed on 22 November 2019).

56. Kulp, S.A.; Strauss, B.H. New elevation data triple estimates of global vulnerability to sea-level rise and coastal flooding. Nat. Commun. 2019, 10, 4844. [CrossRef] [PubMed] 
57. Koop, R.E.; DeConto, R.M.; Bader, D.A.; Hay, C.C.; Horton, R.M.; Kulp, S.A.; Oppenheimer, M.; Pollard, D.; Strauss, B.H. Evolving Understanding of Antarctic Ice-Sheet Physics and Ambiguity in Probabilistic Sea-Level Projections. Earth's Future 2017, 5, 1217-1233. [CrossRef]

58. Jevrejeva, S.; Jackson, L.P.; Grinsted, A.; Lincke, D.; Marzeion, B. Flood damage costs under the sea level rise with warming of $1.5 \circ \mathrm{C}$ and $2 \circ \mathrm{C}$. Environ. Res. Lett. 2018, 13, 074014. [CrossRef]

(C) 2020 by the authors. Licensee MDPI, Basel, Switzerland. This article is an open access article distributed under the terms and conditions of the Creative Commons Attribution (CC BY) license (http://creativecommons.org/licenses/by/4.0/). 